\title{
Taxonomic survey of Agaricomycetes (Fungi: Basidiomycota) in Ontario tallgrass prairies determined by fruiting body and soil rDNA sampling
}

\author{
Chris R.J. Hay ${ }^{1,}$, , R. Greg Thorn ${ }^{1}$, and Clinton R. JaCobs ${ }^{2}$ \\ ${ }^{1}$ Department of Biology, Biological \& Geological Sciences Building, University of Western Ontario, 1151 Richmond Street, \\ London, Ontario N6A 5B7 Canada \\ ${ }^{2}$ Nin.Da.Waab.Jig Heritage Centre, Bkejwanong (Walpole Island First Nation), 2185 River Road North, R.R. 3, Wallaceburg, \\ Ontario N8A 4K9 Canada \\ ${ }^{*}$ Corresponding author: chris.r.j.hay@gmail.com
}

Hay, C.R.J., R.G. Thorn, and C.R. Jacobs. 2018. Taxonomic survey of Agaricomycetes (Fungi: Basidiomycota) in Ontario tallgrass prairies determined by fruiting body and soil rDNA sampling. Canadian Field-Naturalist 132(4): 407-424. http://doi. org/10.22621/cfn.v132i4.2027

\begin{abstract}
The fungal composition of North America's grasslands is poorly known, but an important area of study due to grassland conservation concerns and their close relation to agricultural lands. This study is a survey of Agaricomcyetes from fifteen diverse tallgrass prairies across southwestern Ontario, determined through fruiting body surveys (above-ground) and next-generation sequencing of soil ribosomal DNA (below-ground), and compares the results of these two techniques. The most species rich taxa were the Clavariaceae, Hygrophoraceae, and Entolomataceae, each detected by both techniques, with the addition of the Sebacinaceae and Polyporaceae sensu lato below-ground, and Hymenogastraceae (Hebeloma spp.) and Mycenaceae above-ground. Many of the most abundant species belonged to these species-rich taxa and were highly abundant by either technique. The above-ground surveys found at least 73 species and the below-ground technique 238 operatonal taxonomic units. Although many fine-scale taxa (species and approximate families) were unique to one technique or the other (only eight genetic species were shared between both), the below-ground technique uncovered a greater breadth of higher taxa (mostly equivalent to orders), including ones undetected by the above-ground technique. A review of grassland fungi surveys around the world shows many similarities and the potential for grassland fungal conservation in North America. Given current technological advancements and grassland conservation concerns, it is prudent to further study North America's grassland fungi.
\end{abstract}

Key words: Tallgrass prairie; grassland mycota; fungal conservation; mushrooms; next-generation sequencing; basidiomycetes; survey

\section{Introduction}

Worldwide, grasslands represent the largest terrestrial biome, covering approximately $40 \%$ of the earth's land surface, and are tremendously important for the development of crop and grazing agriculture and the biodiversity of natural grassland remnants (Gibson 2009). The prairies represent the large region of grasslands in central North America. They are characterized by low or no woody plant coverage, consisting mostly of grasses and a high diversity of sparse, broadleaved herbaceous species (Sims 1988). Tallgrass prairies comprise the eastern portion of the central grasslands and have more precipitation (mesic), than the drier mixedgrass and shortgrass prairies further west (xeric; Samson and Knopf 1996). Southwestern Ontario is classified as part of the Temperate Deciduous Forest biome (Whittaker 1975; Archibold 1995), and within that as Mixedwood Plains ecozone (Ecological Stratification Working Group 1995), so there is only a small amount of naturally occurring tallgrass prairie-oak savannah mosaic (Barcza and Lebedyk 2014). This study focussed on tallgrass prairie in southwestern Ontario, though pockets also exist in Ontario further northwest (Quinlan 2005) and northeast (e.g., the Rice Lake plains; Catling et al. 1992). Prairies, particularly tallgrass, are among the most depleted and imperilled ecosystems in the world (Noss et al. 1995; Samson and Knopf 1996; Koper et al. 2010) and tallgrass prairies in Ontario are no exception (Barcza and Lebedyk 2014). Consequently, tallgrass prairie is habitat to many plant and animal species at risk (Rodger 1998; Environment Canada 2014), and perhaps unexplored fungi at risk.

The Agaricomycetes are a class of fungi (phylum Basidiomycota) that include about one-fifth of all fungal species (Kirk et al. 2008) and diverse morphologies of mushrooms (fruiting bodies; Hibbett et al. 2014). Both globally in terrestrial ecosystems and within grasslands and shrublands specifically, Agaricomycetes comprise $50 \%$ of soil fungal diversity (Tedersoo et al. 2014). They include the dominant saprotrophs of plant litter and other species that are pathogens and mutualistsespecially those forming ectomycorrhizal relationships with plant roots (Weiss et al. 2004; Smith and Read 2008; Hibbett et al. 2014). Some species belong to more

A contribution towards the cost of this publication has been provided by the Thomas Manning Memorial Fund of the Ottawa Field-Naturalists' Club. 
than one of these categories or are opportunistic (Griffith and Roderick 2008).

Illuminating the fungal composition of ecosystems by producing species lists and collections of dried specimens is an important first step for fungal conservation by providing basic information to mycologists, conservationists, and governments (Arnolds 1989a; Keizer 1993; Courtecuisse 2001; Bruns 2012). Mushroom forays are often carried out by local naturalist groups, but lists are usually not documented with specimens kept in recognized fungaria, and when they are, identifications of many taxa may be suspect if applied without attention to microscopic characters and thorough consideration of species names outside of incomplete or outdated field guides. The majority of authoritative data are found in herbaria (fungaria), which are increasingly being digitized and compiled (e.g., http:// www.MyCoPortal.org) but still require some care with interpretation of outdated taxonomy and confirmation of identifications (Redhead 1989). Available records reveal regional and ecological gaps where specimens have not been collected.

Given the global extent of grassland cover and the importance of fungi to grassland ecosystems, it is remarkable that no estimate of a grassland mycota has been compiled. Typically, wooded ecosystems are preferred over grasslands for forays and scientific surveys (noted in Griffith and Roderick 2008; e.g., Polach 1992; Castellano et al. 1999; Dewsbury et al. 2006). Grassland mushroom fungi are best known from extensive fruiting body surveys in Europe (e.g., various grasslands in England, Wilkins and Patrick 1939; forest meadow slopes in Poland, Gumińska 1976; and coastal grasslands in the Netherlands, Arnolds 1981). There are also records from soil culturing and fruiting body surveys in Australia (Warcup 1951, 1959; Warcup and Talbot 1962, 1963, 1965), and fewer in North America (shortgrass prairie dung cultures, Wicklow and Angel 1974; alvar grasslands surveys, Mycological Society of Toronto 2005a,b; and a mixedgrass prairie survey, Hay 2013). Many studies from Europe are specific to "waxcap" grasslands, which have received special attention and mycological study due to concerns over land management changes and loss of characteristic fungi in this habitat (Rotheroe et al. 1996; Rotheroe 2001; Newton et al. 2003; Mitchel 2010; Griffith et al. 2013). Other studies are focussed on producing national Red Lists of species potentially at risk (e.g., the Netherlands, Arnolds 1989a). Although there is anecdotal knowledge among mycologists and naturalists of which mushrooms are found in North American grasslands (such as in field guides, e.g., Arora 1986; Barron 1999), a lack of scientific data makes study of distribution and ecology difficult or impossible (Redhead 1989). Thus, syntheses and interpretation of the available data have not been attempted.

Next-generation sequencing (NGS) represents a major advancement in high-throughput sequencing technology and, with the development of taxon-specific
DNA barcodes, has revolutionized biology (Shokralla et al. 2012; Lindahl et al. 2013; Bleidorn 2016). Communities of microorganisms can be characterized through collection of DNA sequences from environmental samples, a process termed "eDNA metabarcoding" (Taberlet et al. 2012). Continual growth of reference datasets such as GenBank and UNITE further facilitates more accurate and thorough classification of DNA sequences obtained through NGS, and improved primers have been developed to target specific fungal taxa based on amplification of ribosomal DNA (rDNA) regions (Asemaninejad et al. 2016; Taylor et al. 2016; De Filippis et al. 2017). Previously hidden fungal diversity is constantly uncovered by NGS when unclassifiable sequences are found (Hibbett et al. 2014; Nilsson et al. 2016). This has improved our understanding of the ecology and distribution of known species, particularly those that are difficult to find through culturing or fruiting body surveys. The "mycobiome" in soils and plants is often studied, albeit at taxonomic scales too coarse to uncover biodiversity at the species level (Peay et al. 2016). Microfungi (i.e., molds; Clarke and Christensen 1981; Maggi et al. 2005) and arbuscular-mycorrhizal fungi (Eom et al. 2000; Stover et al. 2012) have been surveyed in grasslands and many studies conduct microbial surveys from non-taxonomic, chemical perspectives (e.g., McKinley et al. 2005). Agaricomycetes in native grasslands of North America have been explored obliquely in the process of fulfilling other research objectives using NGS in tallgrass prairies of Oklahoma (Penton et al. 2013) and Kansas (Jumpponen et al. 2010; Jumpponen and Jones 2014).

The fungal taxa of a site may be uncovered using fruiting body surveys (or spores, hyphal sheaths on roots, etc.), culture-based approaches, or molecular methods (including NGS), and usually there are disparities among the results of each technique (Horton and Bruns 2001). Seeing differences among results is useful for determining limitations of any one technique and to gain a more accurate view of community composition. Results of molecular techniques have been compared with cultures of grassland or agroecosystem soil samples (Hunt et al. 2004; Lynch and Thorn 2006) and with fruiting body surveys of ectomycorrhizal species in treed ecosystems (Gardes and Bruns 1996; Smith et al. 2007; Porter et al. 2008; Dickie et al. 2009). The only mycological study we found comparing both of the above- and below-ground techniques that we use (specifically fruiting body surveys and NGS high-throughput sequencing) was of dead wood communities (Ovaskainen et al. 2013).

All things considered, the fungal composition of North American grasslands is a large research gap that can now readily be addressed. The objectives of this study are to survey the Agaricomycetes in selected Ontario tallgrass prairies by fruiting body and soil rDNA sampling, and to compare results of fruiting body and soil rDNA sampling techniques. These findings may yield new insights into prairie ecology and management 
in conservation and restoration initiatives, will contribute to better understanding mushroom species biogeography and surveying methods, and will serve as a foundation to inform future research.

\section{Study Area}

This study sampled from fifteen different tallgrass prairie sites across southwestern Ontario, Canada (Figure 1). The sites include prairie remnants and restorations (from agricultural fields) respresenting a diversity of soil types and vegetative cover. We have grouped them into geographic regions and described them from west to east.

Four sites were from the Herb Gray Parkway, a major highway construction project in Windsor, Ontario. Each of the four sites underwent restorative management to remove woody and invasive plants, and had species at risk transplanted from construction zones; hence, they were labeled as "Final Restoration Sites" (FRS; Balsdon and Snyder 2015). Two of these four sites were in west Windsor with loam to loamy sand soils (FRS \#23: $42.273^{\circ} \mathrm{N}, 83.069^{\circ} \mathrm{W}$ and FRS \#32: $\left.42.272^{\circ} \mathrm{N}, 83.070^{\circ} \mathrm{W}\right)$. The other two were in east Windsor with silty clay soils (FRS \#27: $42.229^{\circ} \mathrm{N}$, $82.994^{\circ} \mathrm{W}$ and FRS \#28: $\left.42.228^{\circ} \mathrm{N}, 82.993^{\circ} \mathrm{W}\right)$. We also sampled from two sites in the Ojibway Prairie Provincial Nature Reserve (Ojibway prairie site \#1: $42.263^{\circ} \mathrm{N}, 83.071^{\circ} \mathrm{W}$ and Ojibway prairie site $\# 2$ : $\left.42.261^{\circ} \mathrm{N}, 83.068^{\circ} \mathrm{W}\right)$. The reserve is a large area of tallgrass prairie and oak savannah ecosystems with silty sand to sandy soils in west Windsor near FRS \#23 and FRS \#32.

Five sites were located in Walpole Island First Nation (WIFN), north of Lake St. Clair, Ontario. Two sites were old agricultural fields that have revegetated after being abandoned in recent decades (WIFN sites \#2 and \#3) and three were chosen as representatives of high quality tallgrass prairies with minimal to no agricultural history (WIFN sites \#1, \#4, and \#5). The soils range from silty sand to loam to silty clay. Details regarding these sites and their locations may be obtained through permission from the Nin.Da.Waab.Jig Heritage Centre.

Relatively centrally located in our survey region was the Dutton-Dunwich site $\left(42.643^{\circ} \mathrm{N}, 81.536^{\circ} \mathrm{W}\right)$ located on a railroad line in Elgin County managed by the West Elgin Nature Club and Elgin County Stewardship Council. Despite gravel covering much of the soil and encroachment of woody vegetation, we found a diversity of quality native vegetation and pockets of undisturbed land.

On the southeastern edge of our survey area were two sites in Norfolk County, both restored tallgrass prairies with very sandy soils characteristic of the area: DeMaere prairie $\left(42.685^{\circ} \mathrm{N}, 80.464^{\circ} \mathrm{W}\right)$, managed by the Nature Conservancy of Canada, and Mary \& Peter's prairie $\left(42.641^{\circ} \mathrm{N}, 80.572^{\circ} \mathrm{W}\right)$ managed by private landowners. Blair Flats $\left(43.384^{\circ} \mathrm{N}, 80.373^{\circ} \mathrm{W}\right)$ sits on the north-eastern edge of our survey area, in the

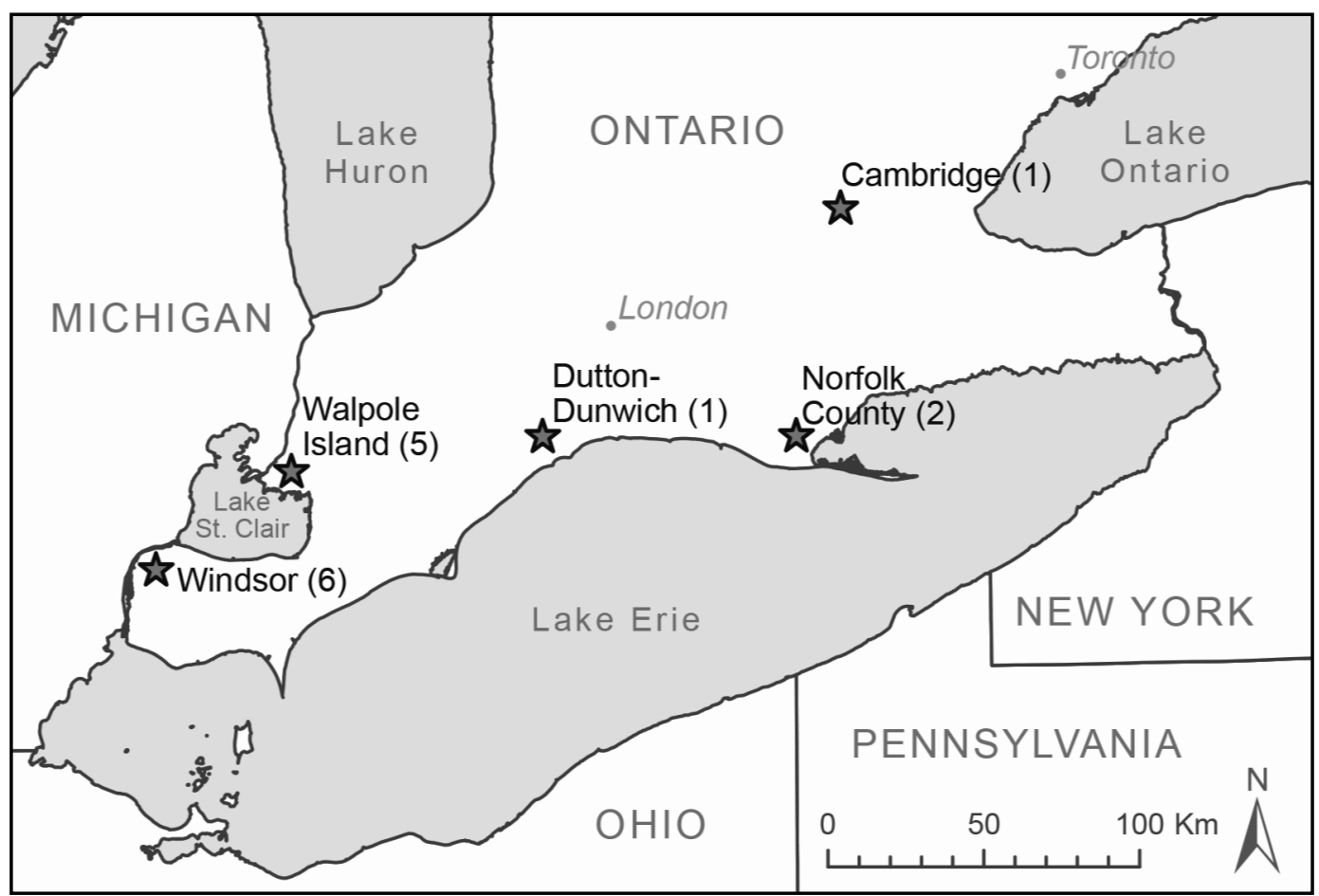

FigURE 1. Map of 15 tallgrass prairie sites sampled across five regions in southwestern Ontario. Site abbreviations are listed in Table 1. 
Township of North Dumfries near Cambridge, Ontario. It was one of our restored tallgrass prairie sites and is managed by the RARE Charitable Research Reserve. It had thick cover of native vegetation and silty clay loam soil.

\section{Methods}

\section{Soil collection and sieving}

Soil samples were collected for NGS. Six, $1 \mathrm{~m}$ square quadrats were sampled across each site to capture maximal variety across the landscape. Single soil cores, $20 \mathrm{~cm}$ deep and $2.5 \mathrm{~cm}$ diameter, were taken from each quadrat corner and from the quadrat centre. All five cores were mixed in one bag per quadrat. Above-ground vegetation and litter was removed from the top of each core. The soil corer was wiped clean using a cloth and $70 \%$ ethanol solution to prevent soil mixing between quadrats. Bags of soil were kept in a cooler with ice packs in the field and transferred to $\mathrm{a}-20^{\circ} \mathrm{C}$ freezer in the lab. Soil was collected from 2009 to 2014 at least once in June or July and once in October by investigators in previous studies (Table 1). Summer and fall samples were kept separate through the full sequencing protocol, yielding two to three timepoints of NGS data per site, though seasonal differences are not examined in the present study. Dutton-Dunwich and Mary $\&$ Peter's prairies were not sampled for soil.

Soil subsamples of $20 \mathrm{~g}$ from each quadrat were mixed with $100 \mathrm{~mL}$ of $0.1 \mathrm{M}$ (moles/L) sodium pyrophosphate for 5-10 minutes to break apart soil colloids. The mixture was poured over stacked sieves with pore sizes $1.18 \mathrm{~mm}, 0.25 \mathrm{~mm}$, and $0.053 \mathrm{~mm}$, and washed with deionized water. The sieve washing technique allows for the capture of plant debris, fungal hyphae, rhizomorphs, and sclerotia, while removing spores, including abundant asexual spores of ascomycetous and zygomycetous molds (Thorn et al. 1996; Lynch and Thorn 2006).

Organic materials were extracted from the sieves and placed in Falcon tubes until $\sim 5 \mathrm{~mL}$ was obtained for each sample. The organic materials included plant roots (and potential fungi on their surfaces) picked from the upper (coarse) sieve with forceps and dark organic matter separated from sand and silt in the middle and lower (fine) sieves, collected with a spatula and broad tip pipette, respectively. Sieves and collecting tools were thoroughly rinsed with deionized water and cleaned using $70 \%$ ethanol between each sample.

\section{Soil DNA extraction, PCR procedures, and submission for NGS}

To ensure cell wall lysis prior to DNA extraction, soil organic matter was lyophilized using a Virtis Bench Top 3.5 L Freeze Dryer (SP Scientific, Stone Ridge, New York, USA) and ground to a floury texture using liquid nitrogen in a sterile mortar and pestle for each sample. DNA extraction was carried out using a Soil Microbe DNA MicroPrep ${ }^{\mathrm{TM}}$ kit (Zymo Research, Irvine, California, USA) following standard protocols. This involved bead-beating samples using a FastPrep $^{\mathrm{TM}}$ FP210 machine (Bio101, Qbiogene, Inc., Carlsbad, California, USA) set at a speed of 4.0 for $30 \mathrm{sec}-$ onds. The concentration of eluted DNA was measured using a Nanodrop2000 Spectrophotometer (ThermoFisher, Mississauga, Ontario, Canada).

PCR was carried out by combining solutions to a total of $25 \mu \mathrm{L}$ in microtubes: 3.0 to $5.0 \mu \mathrm{L}$ molecular grade water (remaining difference), $3 \mu \mathrm{L}$ each of forward and reverse primers, $12.5 \mu \mathrm{L}$ ToughMix (Quanta Biosciences, Beverly, Massachusetts, USA), 1.0 to 3.0 $\mu \mathrm{L}$ template DNA (at $\sim 20 \mathrm{ng} / \mu \mathrm{L}$ ), and $0.5 \mu \mathrm{L}$ loading dye. The primers used were LSU200-F and LSU481-R (AACKGCGAGTGAAGMGGGA and TCTTTCCCT-

TABle 1. Site visits for soil and/or fruiting bodies at 15 tallgrass prairie sites across southwestern Ontario. Footnotes identify principal investigators associated with sampling.

\begin{tabular}{|c|c|c|c|}
\hline Site & Abbreviation & Soil sampling & Fruiting body surveys \\
\hline FRS \#23 & HA & July and October 2014 & June, July and October $2015^{\S}$ \\
\hline FRS \#32 & HB & July and October 2014 & June, July and October $2015^{\S}$ \\
\hline Ojibway prairie site \#1 & $\mathrm{OA}$ & July and October $2014^{\ddagger}$ & June, July and October $2015^{\S}$ \\
\hline Ojibway prairie site \#2 & OB & July and October $2014^{\ddagger}$ & June, July and October $2015^{\S}$ \\
\hline FRS \#27 & $\mathrm{HC}$ & July and October 2014 & June, July and October $2015^{\S}$ \\
\hline FRS \#28 & HD & July and October 2014 & June, July and October $2015^{\S}$ \\
\hline Walpole Site \#1 & WA & June and October $2009^{*}$, October $2014^{\ddagger}$ & October 2014, July and October $2015^{\S}$ \\
\hline Walpole Site \#2 & WB & June and October $2009^{*}$, October 2014 & October 2014, July and October $2015^{\S}$ \\
\hline Walpole Site \#3 & WC & June and October $2009^{*}$ & not sampled \\
\hline Walpole Site \#4 & WD & June and October $2009^{*}$, October $2014^{*}$ & October 2014 , July and October $2015^{\S}$ \\
\hline Walpole Site \#5 & WE & June and October $2009^{*}$, October 2014 & October 2014, July and October $2015^{\S}$ \\
\hline Dutton-Dunwich & DD & not sampled & June and October $2015^{\S}$ \\
\hline Mary \& Peter's prairie & MP & not sampled & June and October $2015^{\S}$ \\
\hline DeMaere prairie & $\mathrm{DM}$ & July and October $2014^{\dagger}$ & October 2014, July and October $2015^{\S}$ \\
\hline Blair flats & $\mathrm{BF}$ & July and October 2014 & October 2014 , August and October $2015^{\S}$ \\
\hline
\end{tabular}

${ }^{*}$ Chokroborty-Hoque (2011).

Catomeris (2015).

^Allan (2017).

$\S$ The present study. 
CACGGTACTTG, respectively), which target $\sim 250$ nucleotide bases at the D1 large subunit (LSU) region of ribosomal DNA (Asemaninejad et al. 2016). Barcodes were included with forward and reverse primers to discriminate among site visits. Soil templates were PCR-amplified using a Biometra T1 Thermocycler (Montreal Biotech, Dorval, Quebec, Canada) programmed as follows: $94^{\circ} \mathrm{C} 2 \mathrm{~min}, 30$ cycles of $94^{\circ} \mathrm{C}$ $30 \mathrm{sec}, 60^{\circ} \mathrm{C} 30 \mathrm{sec}, 72^{\circ} \mathrm{C} 18 \mathrm{sec}$, and holding at $4^{\circ} \mathrm{C}$ after cycling. PCR products were checked for successful amplification by gel electrophoresis using $1.0 \%$ $(\mathrm{w} / \mathrm{v})$ agar-agar gels in $1 \times \mathrm{TAE}$ buffer with $0.5 \mu \mathrm{g} / \mathrm{mL}$ ethidium bromide. PCR products from each of the six quadrats were pooled to one tube per site visit, lyophilized, and rehydrated before being submitted for paired-end Illumina MiSeq high-throughput sequencing using a $2 \times 300 \mathrm{kit}$. Sequencing was conducted by the London Regional Genomics Centre (Robarts Research Institute, London, Ontario, Canada).

\section{NGS data processing and taxonomic annotation}

Raw soil sequence data following Illumina MiSeq were submitted to the European Nucleotide Archive (ENA) by sites, under project accession number PR JEB19932. The raw data were processed using a pipeline developed by Greg Gloor, Biochemistry, University of Western Ontario, London, Ontario, Canada which is available on GitHub (http://www.github.com/ ggloor/miseq_bin/tree/Jean). PANDAseq overlapped forward and reverse sequence reads with a minimum overlap of 30 nucleotides (Andre et al. 2012). Sequence data from three Illumina MiSeq runs were processed separately until this stage when they were combined, using the script workflow_combined_runs.sh from the aforementioned GitHub. A number of programs are used in this workflow. UCLUST was used to create identical sequence unit clusters (ISUs, $100 \%$ similarity), then UCHIME was used to find and remove chimeric sequences (Edgar et al. 2011). This removed 22600 possibly chimeric sequences from the 529300 unique sequences. UCLUST was then used to further cluster ISUs into operational taxonomic units (OTUs, $97 \%$ similarity) with a most common, centroid seed OTU sequence (Edgar 2010). A 99\% similarity cutoff has been used to delimit yeast species OTUs from sequences of the D1-D2 LSU(25S) region of rRNA (Peterson and Kurtzman 1991), but we chose $97 \%$ because our amplicons were from only the most variable (D1) part of this region. Our sequence clustering produced 14300 OTUs. The read counts were attached to OTUs, using a $0.1 \%$ cutoff in any sample.

To capture Agaricomycete OTUs only, sequences were filtered using the Ribosomal Database Project (sequence classifier, gene database: fungal LSU training set 11; Wang et al. 2007) and a neighbour-joining tree to produce an Agaricomycete clade after alignment using MUSCLE (Edgar 2004) in MEGA6 (Tamura et al. 2013). Agaricomycete OTUs were annotated to a finer scale by querying through NCBI's GenBank database using the Basic Local Alignment Search Tool for nucleotide sequences (blastn) to find matches. Specieslevel names were applied only when query cover and percent identity were both greater than $97 \%$ and no competing species names were retrieved within this range. Filtering by taxonomic identity for Agaricomycetes left 281 OTUs. These Agaricomycete OTU sequences were submitted to GenBank under accession numbers KY353514-KY353794. OTUs were sorted into coarser taxonomic groups as minor (ca. family) and major (ca. order) clades based on their assigned taxonomic annotation and placement in a neighbourjoining tree.

\section{Fruiting body field surveys and sequencing of specimens}

Fruiting body collection allowed us to sample a larger area than soil coring and provided us with voucher specimens as tangible records for morphological and sequence-assisted identifications. Surveys were conducted at each site in a wandering design covering on average 2.2 ha and ranging from $\sim 0.2$ to $10 \mathrm{ha}$. A global positioning system (GPS) receiver was used to ensure soil sampling quadrats were surveyed and to evenly search remaining ground of each site. Fruiting bodies were counted, genetic individual counts estimated from clusters of fruiting bodies, and a voucher specimen collected for each morphospecies (conservatively estimated in the field). Each voucher was documented with a specimen code, photos, GPS coordinates, and habitat notes, and was preserved using a food dehydrator before being stored in a paper herbarium packet. We conducted fruiting body surveys two to three times for each site on dates ranging from October 2014 to 2015 (Table 1). WIFN site \#3 was not sampled for fruiting bodies. Dried specimens were deposited at the University of Western Ontario herbarium (UWO) and associated photos and data (including which identification resources were consulted) are available online (http:// www.mushroomobserver.org/species_list/show_speci es_list/652).

Genomic DNA was extracted from mushroom specimens using the GeneJET Plant Genomic DNA Purification Mini Kit (Thermo Fisher Scientific Inc., Mississauga, Ontario, Canada), starting with bead beating in a FastPrep ${ }^{\mathrm{TM}}$ FP120 machine (Bio101, Qbiogene Inc., Carlsbad, California, USA) set at 4.0 for 30 seconds. The concentration of eluted DNA was measured using a Nanodrop2000 Spectrophotometer. PCR was carried out by combining solutions to a total of $25 \mu \mathrm{L}$ in microtubes: 9.0 to $9.5 \mu \mathrm{L}$ molecular water (remaining difference), 1.25 each of forward and reverse primers, 12.5 FroggaMix (FroggaBio, Toronto, Ontario, Canada), and finally 0.5 to $1.0 \mu \mathrm{L}$ template DNA (at $\sim 20 \mathrm{ng} / \mu \mathrm{L}$ ). We used the primers ITS8F and LR3-mod (AGTCGTA ACAAGGTTTCCGTAGGTG and GGTCCGTGTTT CAAGACGGG, respectively), which cover $\sim 1300$ bases, including partial SSU, complete ITS1, 5.8S, and ITS2, and partial LSU (Vilgalys and Hester 1990; Dentinger et al. 2010). This overlaps the region amplified by LSU200-F and LSU481-R for the soil samples 
(which is important for our later analyses comparing sequences between the above- and below-ground techniques). Fruiting body templates were PCR-amplified using a MWG Biotech Primus96 (Huntsville, Alabama, USA) thermocycler programmed as follows: $94^{\circ} \mathrm{C} 1$ min, 30 cycles of $94^{\circ} \mathrm{C} 30 \mathrm{sec}, 58^{\circ} \mathrm{C} 30 \mathrm{sec}, 72^{\circ} \mathrm{C} 1$ min $30 \mathrm{sec}$, an extension time of $72^{\circ} \mathrm{C}$ for $7 \mathrm{~min}$, and finally holding at $4^{\circ} \mathrm{C}$. Successful PCR products were cleaned using the EZ-10 Spin Column PCR Products Purification Kit (Bio Basic Canada Inc., Markham, Ontario, Canada) and submitted for Sanger sequencing (Sanger et al. 1977). Each PCR sample was submitted four separate times with different primers to cover the entire amplified length: ITS8F, LS1R-mod (CTTAAG TTCAGCGGGTAGTCC), LS1-mod (GGACTACCC GCTGAACTTAAG), and LR3-mod (Vilgalys and Hester 1990; Hausner et al. 1993; Dentinger et al. 2010). Sequencing was conducted by the London Regional Genomics Centre (Robarts Research Institute, London, Ontario, Canada).

Fruiting body sequences were assembled and checked for errors using Geneious 8.0.5 (Kearse et al. 2012). Assembled sequences were queried through GenBank to find matches that might help to inform identification of specimens. Fruiting bodies were identified using taxonomic keys, involving navigating through indicative macro- and micro-scopic features, chemical tests, and ecological context. Sequences were deposited in GenBank under accession numbers KX215469-KX215471 and KY706152-KY706198 (Supplementary Data Sheets A and E; Hay et al. 2018).

\section{Statistical analyses}

To compare soil rDNA sequencing and fruiting body surveys, data from WIFN site \#3, Dutton-Dunwich prairie, and Mary \& Peter's prairie were excluded because these sites were not sampled with both techniques. To ensure soil data were equally weighted across sites, two additional quadrats in DeMaere prairie were excluded to maintain consistency of six quadrats per site, and Walpole Island site samples from October 2009 were excluded to maintain two samples per site from each season (early summer and fall).

Average relative abundances of OTUs were calculated by dividing read values by the sum reads for each site visit (column) and averaging for each OTU (row) across all site visits. Shared genetic species were found by bringing OTU and fruiting body sequences into MEGA 6, aligning with MUSCLE, trimming to OTU length (the limiting factor), then using Microsoft Excel 2013 (version 15.0.4737.1001, Microsoft Corporation, Redmond, Washington, USA) to highlight duplicate sequences. Venn diagrams illustrating degrees of overlap at different taxonomic scales were created using the venneuler package (Wilkinson 2011) in RStudio (RStudio Team 2016). A map of site regions was produced using QGIS 2.18.15 (QGIS Development Team 2017) and open source boundary data (Statistics Canada 2011; United States Census Bureau 2016).

\section{Results}

Fruiting body survey totals and common taxa

From the 14 sites surveyed two to three times for fruiting bodies, at least 73 different species were found across 45 genera, of which 57 were identified to species level. Sequences were obtained from 50 collections representing at least 40 different species. The number of species found ranged from zero to 22 , and was on average nine species per site (Supplementary Data Sheets A and B; Hay et al. 2018).

The most abundant species by counts of estimated genetic individuals (clusters of similar fruiting bodies) were Entoloma sericeum (Bull.) Quél. ("silky pinkgill"; note: because there are no standard common names for fungal species, including mushrooms, common names when they exist are included in quotation marks upon first occurrences), which was found covering a large proprotion of the ground at Blair Flats during a fall survey, unidentified white Clavaria species, Cotylidia undulata (Fr.) P. Karst. ("stalked rosette") found only at DeMaere prairie, and unidentified Clitopilus and Mycena (sensu lato, white) species (Table 2). The species occurring across the most (four) sites were Entoloma subgenus Leptonia (diaphanous, umbilicate), Marasmiellus sp., and Vascellum curtisii (Berk.) Kreisel (Table 2). The most species rich minor clades (ca. families) were the Entolomataceae, Hygrophoraceae, Hymenogastraceae (mostly Hebeloma spp.), Clavariaceae, and Mycenaceae, with 17 to five species each (Figure 2).

\section{Soil rDNA sampling totals and common taxa}

After quality filtering, removing rare OTUs, and removing sequences of non-agarics, 1194767 reads of 281 OTUs from 30 samples (site visits) remained, an average of 39826 reads and 30 OTUs per sample (Supplementary Data Sheet D; Hay et al. 2018). Removal

TABLE 2. The 17 most abundant fruiting body species (four or more individuals), as measured by the number of individuals, estimated from groups or clusters of fruiting bodies.

\begin{tabular}{lcc}
\hline \hline Species & Individuals & Sites \\
\hline Entoloma sericeum & 17 & 2 \\
Clavaria sp. (white) & 12 & 2 \\
Cotylidia undulata & 12 & 1 \\
Clitopilus sp. & 10 & 3 \\
Mycena sp. (sensu lato, white) & 10 & 3 \\
Entoloma subgenus Leptonia & 9 & 4 \\
(diaphanous, umbilicate) & & \\
Marasmiellus sp. & 9 & 4 \\
Vascellum curtisii & 9 & 4 \\
Hygrocybe conica (group) & 7 & 3 \\
Mutinus cf. elegans & 6 & 3 \\
Tubaria furfuracea & 6 & 3 \\
Astraeus hygrometricus & 6 & 1 \\
Entoloma incanum & 4 & 2 \\
Hebeloma cf. sporadicum & 4 & 2 \\
Psathyrella ammophila & 4 & 2 \\
Hebeloma cf. dunense & 4 & 1 \\
Omphalina pyxidata & 4 & 1 \\
\hline \hline
\end{tabular}


Below-ground (OTUs)

25
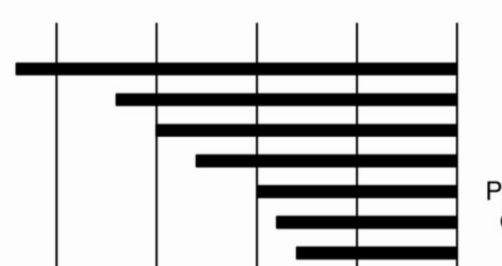

-

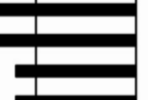

ت1

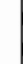

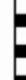

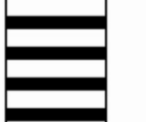

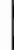

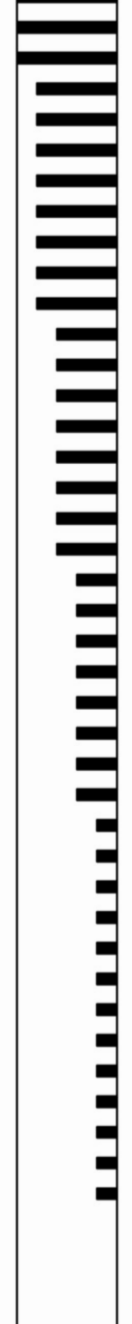

\section{Minor Clades}

Clavariaceae

Entolomataceae

Sebacinaceae

Hygrophoraceae

Polyporaceae sensu lato

Gomphales subclade

Pluteaceae

Tricholomataceae

Auriculariaceae

Psathyrellaceae

Inocybaceae

Mycenaceae

Bolbitiaceae

Marasmiaceae

Ceratobasidiaceae

Hymenochaetaceae

Thelephoraceae

Hymenogastraceae

Atheliaceae

Boletaceae

Corticiaceae

Hydnaceae

Hydnodontaceae

Russulaceae

Tulasnellaceae

Agaricaceae

Strophariaceae

Cortinariaceae

Auric. incertae sedis

Crepidotaceae

Hydropoid

Russ. unknown family

Typhulaceae

Phallaceae

Botryobasidiaceae

Canth. i.s. (Minimedusa)

Canth. unknown family

Geastraceae

Lyophyllaceae

Physalacriaceae

Stephanosporaceae

Repetobasidiaceae

Suillaceae

Amanitaceae

Auriscalpiaceae

Cantharellaceae

Cyphellaceae

Jaapiaceae

Lachnellaceae

Melanogastraceae

Pterulaceae

Schizoporaceae

Sclerodermataceae

Thel. unknown family

Nidulariaceae

Hydnangiaceae

Paxillaceae

Peniophoraceae

\section{Above-ground (Mushroom spp.)}

$\begin{array}{llllll}0 & 5 & 10 & 15 & 20 & 25\end{array}$

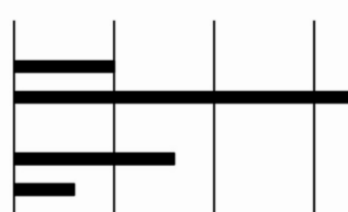

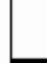
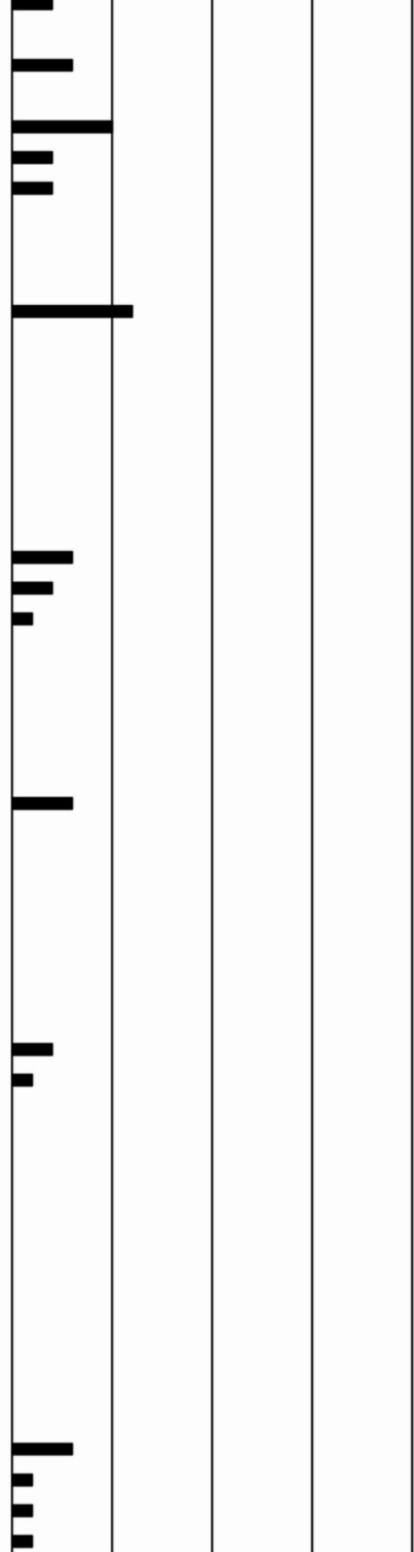

FigURE 2. Richness of operational taxonomic units (OTUs) and species within minor clades (ca. family level), comparing results of soil rDNA NGS ("below-ground") with fruiting body ("above-ground") surveys. Richness here is a function of the composition of all sites, taxonomic diversity in each clade, and detection ability of each technique. 
of extraneous sampling data reduced the number of Agaricomycete OTUs from 281 to 238 OTUs which were used in the analyses following. Six OTUs remained unknown, because query results represented diverse taxa and OTU phylogram branches showed low bootstrap values. These OTUs were included in specieslevel analyses but were not counted as a unique minor or major clade. Excluding the clades for the unknowns (one minor and one major), diversity spanned 55 minor clades and 19 major clades (Supplementary Data Sheet C; Hay et al. 2018).

The OTUs from soil rDNA sampling with highest relative read abundances were Minimedusa polyspora (Hotson) Weresub \& P.M. LeClair and Ceratobasidiaceae sp. 1 that do not produce fruiting bodies visible to the naked eye, and Hygrocybe conica ("witch's hat") group sp. 3 and Mutinus elegans (Mont.) Fisch. ("elegant stinkhorn") that do (Table 3). The OTUs occurring across the most sites were $M$. polyspora, Fomitopsidaceae sp., Entoloma sp. 3, Gomphales sp. 3, and Lyophyllaceae sp. 2 (Table 3; Supplementary Data Sheet D; Hay et al. 2018). The most OTU rich minor clades (ca. families) were the Clavariaceae, Entolomataceae, Sebacinaceae, Hygrophoraceae, and Polyporaceae sensu lato, with 22 to 10 OTUs each (Figure 2).

\section{Collective results and comparison between above- and below-ground techniques}

Across both sampling techniques, the most species and OTU rich clades found were the Clavariaceae, Hygrophoraceae, and Entolomataceae (Figure 2). Many minor clades were only found using the below-ground technique (soil rDNA NGS), not by above-ground sampling (fruiting body surveys), whereas relatively few were unique to above-ground sampling. Most minor clades unique to the below-ground sampling technique seldom or never produce conspicuous fruiting bodies (e.g., Sebacinaceae) or may represent uncommon species that were overlooked during sampling. Minor clades unique to the above-ground sampling technique are either mycorrhizal incidentals (Hydnangiaceae and Paxillaceae) or saprobes apparently limited to colonization of litter above the soil surface (Nidulariaceae and Peniophoraceae). Other taxa not exclusive to one technique were still found disproportionately by one or the other. For example, in the Clavariaceae 22 OTUs were found below- and only five above-ground. In con-
TABLE 3. The 15 most abundant soil rDNA operational taxonomic units (OTUs), as measured by average relative abundance (average relative abundance of OTU in each sample i.e., site visit, averaged across all samples).

\begin{tabular}{lcr}
\hline \hline & $\begin{array}{c}\text { Average } \\
\text { relative } \\
\text { abundance }\end{array}$ & Sites \\
OTU & 0.0978 & 12 \\
\hline Minimedusa polyspora & 0.0393 & 4 \\
Ceratobasidiaceae sp. 1 & 0.0387 & 4 \\
Hygrocybe conica group sp. 3 & 0.0385 & 4 \\
Mutinus elegans & 0.0333 & 10 \\
Gomphales sp. 3 & 0.0318 & 7 \\
Hygrocybe conica group sp. 2 & 0.0313 & 5 \\
Russulales sp. 1 & 0.0248 & 5 \\
Sebacinaceae sp. 2 & 0.0227 & 6 \\
Tricholomataceae sp. 3 & 0.0223 & 6 \\
Mycena epipterygia sp. 1 & 0.0201 & 10 \\
Entoloma sp. 3 & 0.0185 & 10 \\
Fomitopsidaceae sp. & 0.0181 & 8 \\
Hymenogastraceae sp. & 0.0179 & 4 \\
Hypochnicium sp. & 0.0163 & 3 \\
Hypholoma sp. &
\end{tabular}

trast 17 OTUs or species of Entolomataceae were found in each of above- and below-ground techniques.

\section{Shared species and degrees of overlap at different taxonomic scales}

There were eight species detected by both the above and below-ground techniques that had identical sequences ("shared species"; Table 4). Some of these shared species were found by both methods at the same site (e.g., C. undulata), by only one technique or the other across different sites (e.g., Clavaria cf. fragilis Holmsk. ["white spindles"]), or a combination of these two scenarios (e.g., V. curtisii). Several species seem to correspond between techniques (Tables 2 and 3), but are unconfirmed: Mycena epipterygia (Scop.) Gray sp. 1 OTU with the abundant Mycena sp. (sensu lato, white) fruiting bodies for which sequencing failed, the Hymenogastraceae sp. OTU with Hebeloma spp. fruiting bodies, and species with identical names between both tables: the $H$. conica group spp., M. elegans, and species of Entoloma.

The degree of overlap between fruiting body and soil rDNA sampling depends on the taxonomic scale in consideration, as seen in Venn diagrams (Figure 3). At the finest scale of genetic species only eight species were

TABLE 4. Detection of shared species (identical sequences) across sites via fruiting body surveys (above-ground - A), rDNA soil sampling (below-ground - B), or both (AB). Site abbreviations as in Table 1.

\begin{tabular}{|c|c|c|c|c|c|c|c|c|c|c|c|c|}
\hline Species & HA & HB & $\mathrm{OA}$ & OB & $\mathrm{HC}$ & HD & WA & WB & WD & WE & DM & $\mathrm{BF}$ \\
\hline Arrhenia cf. acerosa & A & & & & & & & & & A & B & \\
\hline Clavaria cf. acuta & & & B & $\mathrm{B}$ & B & & & A & $\mathrm{B}$ & & & \\
\hline Clavaria cf. fragilis & & $\mathrm{B}$ & & & & & & & A & & & \\
\hline Cotylidia undulata & & & & & & & & & & & $\mathrm{AB}$ & \\
\hline Entoloma incanum & & B & B & $\mathrm{B}$ & & & & & $\mathrm{AB}$ & A & & \\
\hline Entoloma cf. tubaeforme & $\mathrm{AB}$ & A & & & & & & & & A & & \\
\hline Hygrocybe conica group & B & B & $\mathrm{B}$ & $\mathrm{B}$ & & B & B & $\mathrm{A}$ & & $\mathrm{AB}$ & & \\
\hline Vascellum curtisii & B & & & B & & & A & & $\mathrm{AB}$ & $\mathrm{AB}$ & & \\
\hline
\end{tabular}




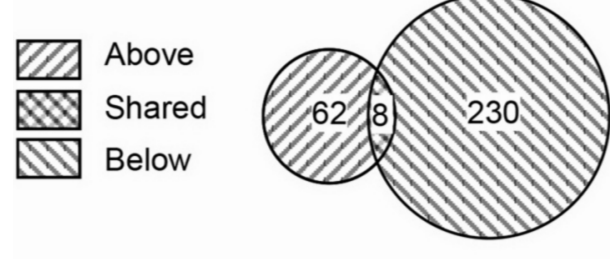

a) Species

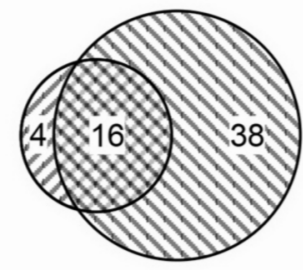

b) Minor Clades

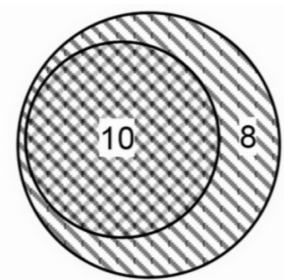

c) Major Clades

FIGURE 3. Area-proportional Venn diagrams comparing below-ground (soil rDNA high throughput sequencing) and aboveground (fruiting body survey) richness at three taxonomic scales: a. genetic species (identical sequences of operational taxonomic units with fruiting body sequences), b. minor clades (ca. family), and c. major clades (ca. order).

shared, representing $11 \%$ of above-ground and $3 \%$ below-ground diversity (Figure 3a). At the minor clade level (ca. family) 16 minor clades were shared, representing $76 \%$ of above-ground minor clades and $30 \%$ of those below-ground (Figure $3 \mathrm{~b}$ ). At the major clade level (ca. order) all 10 major clades found aboveground were also found below-ground, representing $56 \%$ of below-ground major clades (Figure $3 \mathrm{c}$ ). This shows that even at a coarse taxonomic scale (major clades), fruiting body surveys failed to detect the full range of diversity in the soil-inhabiting Agaricomycetes.

\section{Discussion}

\section{A grassland mycota}

Combining our above-ground survey data with selected grassland studies from around the world (Wilkins and Patrick 1939; Warcup 1951, 1959; Warcup and Talbot 1962, 1963, 1965; Wicklow and Angel 1974; Gumińska 1976; Arnolds 1981; Mycological Society of Toronto 2005a,b; Hay 2013; Detheridge et al. 2018) we were able to compile a grassland mycota and identify where tallgrass prairies fit in this context. Almost 500 species of Agaricomycetes were reported among the eight groups of studies examined (including ours). One fifth of species were reported in two or more groups of studies. The most common species were Agaricus campestris L. ("meadow mushroom"), Hygrocybe conica (Schaeff.) P. Kumm. ("witch's hat"), $H$. miniata (Fr.) P. Kumm. ("vermillion waxcap"), Cuphophyllus virgineus (Wulfen) Kovalenko ("snowy waxcap"), E. sericeum, and Lycoperdon perlatum Pers. ("gem-studded puffball"). The most commonly reported genera were Agaricus, Bovista, Coprinopsis, Hygrocybe, Lycoperdon, and Parasola, and the genus with the most reported species was, by far, Entoloma (64 species). All these species and genera were found in our study except for $L$. perlatum. Although we initally identified several puffball specimens as L. perlatum, we corrected our identification to $V$. curtisii after microscopic spore inspection. Entoloma was also our most speciose genus at 15 species.

We found at least six gasteroid species and they were not limited to sites with any specific conditions or to any one region. Common genera from our study and others in our review include small puffballs from Bovista, Lycoperdon, and Vascellum; large puffballs represented by Calvatia spp. and Mycenastrum corium (Guers.) Desv. ("leathery puffball"; Mycological Society of Toronto 2005b); and the stinkhorns Phallus or Mutinus. Gasteroid and secotioid species are typical in hot dry environments (e.g., Gabel and Gabel 2011; Tomaszewska et al. 2015). The secotioid species Chlorophyllum agaricoides (Czern.) Vellinga ("puffball agaric"), Battarrea phalloides (Dicks.) Pers. ("scaleystalked puffball"), and others were found in arid Saskatchewan mixedgrass prairie (Hay 2013), but no secotioid taxa were encountered in our surveys. We suspect that Ontario tallgrass prairies, but perhaps not all tallgrass prairies, are too moist for them.

Most grassland surveys, including our own, encountered species associated with living or dead trees and shrubs. Wood decomposers may appear when deadfall is available or on litter with enough lignin content (e.g., Galerina spp. from Arnolds [1981]; Trametes and Peniophora spp. from the present study and by Warcup and Talbot [1963]; Tubaria spp. from multiple studies). However, wood decomposing fungi have been found in subsurface soil (Goos 1960; Lynch and Thorn 2006), so our Polyporaceae sensu lato OTUs may represent a natural component of tallgrass prairie soils. The rarely reported (and perhaps of conservation importance) Polyporus cryptopus Ellis \& Barthol. ("prairie polypore") is an exception to its genus, attached to grass roots rather than wood, and is unique to North American grasslands. There are several collections from the central USA states (e.g., Cripps 2011) and fewer from the Canadian prairies (Saskatchewan: Hay 2013; Ontario: previously collected from WIFN Site \#4 - RGT 090616/sn, UWO). It has been suggested to be a synonym of the Eurasian species now known as Picipes rhizophilus (Pat.) J.L. Zhou \& B.K. Cui (Zhou et al. 2016) but studies of type material of both are required for confirmation. Ectomycorrhizal species (associated with the roots of living trees or shrubs) are also reported in grassland surveys, usually only when trees are nearby. This includes species of Hebeloma, Cortinarius, Russula, and Suillus from the present study, and Hebeloma spp. reported in other studies (Wilkins and Patrick 1939; Arnolds 1982). However, some ectomy- 
corrhizal fungi partner with small perennial plants such as Lechea mucronata Raf. [Cistaceae], recorded as Lechea villosa Ell. from a grassland site in the same county as our sandy sites (DeMaere prairie and Mary $\&$ Peter's prairie; Malloch and Thorn 1985). The Sebacinaceae are best known for being included in mycorrhizal partnerships with a wide diversity of plants (Weiss et al. 2004) but may also be endophytes (Weiss et al. 2011) or of unresolved ecologies (Tedersoo et al. 2010). Many Sebacinaceae OTUs were detected in the below-ground portion of our study and a similar study from agricultural soils in Michigan, USA (Wong 2012). Above-ground fruiting bodies are rarely reported, probably due to their inconspicuous corticioid nature, although species of Sebacina were cultured in studies by Warcup and Talbot $(1962,1965)$. Many endophytic and parasitic taxa produce inconspicuous fruiting bodies and so are more easily detected by culturing or sequencing, as demonstrated with the Sebacinaceae in our study and review.

Decomposers of above-ground plant litter are commonly reported from fruiting body surveys when methods include litter searches. The most commonly reported genera are Parasola and Mycena spp. (though some of the species may grow from the soil, not litter), and appearing in fewer studies Cyathus, Nidula, and Marasmiellus spp. Our study found all of these taxa, showing the importance of including careful litter examination when conducting complete surveys. Coprophilous species are often conspicuous from sites actively managed by large grazing mammals (e.g., sheep in Wilkins and Patrick [1939]; cattle in Wicklow and Angel [1974]; American Bison [Bison bison] in Hay [2013]), but most grasslands receive some dung from wildlife (e.g., Pronghorn Antelope [Antilocapra americana], rabbits, and voles). Commonly reported taxa from our review were Coprinopsis spp. (especially Coprinopsis nivea (Pers.) Redhead, Vilgalys \& Moncalvo ["snowy inkcap mushroom”]), Panaeolus spp. (esp. Panaeolus papilionaceus (Bull.) Quél. ["petticoat mottlegill"]), Protostropharia semiglobata (Batsch) Redhead, Moncalvo \& Vilgalys ("dung roundhead"), and Deconica coprophila (Bull.) P. Karst. (“dung-loving Psilocybe”). Our study included no sites with large grazing mammals and no fruiting bodies were observed on any small dung examined, so all the coprophilous fungi listed here were noticeably absent from our study.

Terrestrial saprobic species in grasslands cover a wide array of taxonomic groups. Agaricus campestris was present across more studies than any other species, with other agaricoid members of the Agaricaceae reported moderately frequently (genera Chlorophllum, Macrolepiota, and Lepiota) and other Agaricus spp. less fequently. From other families, Marasmius oreades (Bolton) Fr. ("fairy ring mushroom") and Clitocybe spp. were commonly reported, Melanoleuca spp. moderately, and Volvariella sp. and Volvopluteus gloiocephalus (DC.) Vizzini, Contu \& Justo ("rose-gilled grisette") less frequently. Aside from A. campestris and Clitocybe dealbata (Sowerby) Gillet ("ivory funnel") found at one of our sites, we did not find any of these taxa in our tallgrass prairie surveys. Many other terrestrial saprobic taxa are considered nutrient-loving due to their abundance in sites supplemented with dung or artificial fertilizers, specifically species of the Psathyrellaceae (genera: Coprinellus, Coprinopsis, Panaeolus, Parasola, Psathyrella), Strophariaceae (genera: Agrocybe, Deconica, Stropharia), and genera from other families: Conocybe, Marasmius, and Psilocybe (Arnolds 1988, 1989b; Mycological Society of Toronto 2005b). We encountered few of these nutrient-loving species in our tallgrass prairie surveys (Coprinopsis lagopus (Fr.) Redhead, Vilgalys \& Moncalvo ["harefoot inkcap"], Parasola cf. conopilus (Fr.) Örstadius \& E. Larss. ["conical brittlestem"], and Stropharia coronilla (Bull.) ["garland Stropharia"]), suggesting Ontario tallgrass prairies are naturally relatively nutrient-poor.

We found more Clavariaceae, Hygrocybe, and Entoloma (CHE) species in Ontario tallgrass prairies than the other terrestrial surveys of North American grasslands (Mycological Society of Toronto 2005a,b; Hay 2013). In contrast to the terrestrial saprobic and nutrient-loving taxa, these fungi prefer nutrient-poor grasslands, such as the unimproved waxcap grasslands of Europe (Arnolds 1989a; Rotheroe et al. 1996; Detheridge et al. 2018). Most non-lignicolous Clavariaceae species are believed to be biotrophic (Birkebak et al. 2013) and grassland Hygrocybe species are biotrophic with grasses (Griffith et al. 2014). In addition, these two taxa have correlated diversity across grassland sites, but not with Entoloma (Newton et al. 2003). Most species of Entoloma are believed to be saprobic (Noordeloos 2004) with few known parasitic (Agerer and Waller 1993; Czederpiltz et al. 2001) or mycorrhizal (Kobayashi and Yamada 2003; Rinaldi et al. 2008) exceptions. We suggest grassland Entoloma species may also be biotrophic in some way, because even Entolo$m a$ species growing on dead wood are not readily cultured (R.G.T. pers. obs.). Detheridge et al. (2018) consider the CHE taxa biotrophic and group them as one of five fungal ecological functional groups. The abundance of these taxa suggests similar ecological dynamics are at play between tallgrass prairies and European waxcap grasslands, in contrast to drier, nutrient-rich, or agriculturally improved grasslands. Besides the CHE taxa, we found Arrhenia cf. acerosa (Fr.) Kühner ("moss oysterling"), which is associated with ground-dwelling mosses (usually in open grassy areas of woods but apparently also in grasslands, e.g., forest meadows; Gumińska 1976). Investigations are under way to determine if lowland specimens of $A$. cf. acerosa are distinct from arctoalpine ones originally described by Fries (1821; Voitk 2017).

Waxcap grassland surveys focus on surveying from five taxonomic groups to assess grassland quality: Clavariaceae (C) ("coral fungi"), Hygrocybe (H) ("wax- 
caps"), Entoloma (E) (“pinkgills"), Geoglossaceae (G ["earth tongues"], Ascomycota; not included in our survey), and Dermoloma (D; not detected in our survey; Rotheroe et al. 1996). Ratios between taxa have been examined to compare community composition among grasslands (Newton et al. 2003) though the initial use of this system was to highlight sites with high conservation value by uniformly sampling across sites on a national or international scale (Rotheroe et al. 1996). In a comparison of recent surveys of Welsh grasslands, Griffith et al. (2013) found the number of species within each taxonomic group to be $19 \mathrm{C}, 35 \mathrm{H}$, and $46 \mathrm{E}$. Across all our sites in total we found $4 \mathrm{C}, 6 \mathrm{H}$, and $14 \mathrm{E}$. Our study is less extensive by sampling area and effort, but a roughly similar ratio was found and many species from our study were also detected in theirs: two Clavariaceae (Clavaria cf. acuta Sowerby ["pointed fairy club"], C. cf. fragilis), all six of our Hygrocybe and Cuphophyllus species, and over a third of our Entoloma species (Entoloma cf. griseocyaneum (Fr.) P. Kumm. ["felted pinkgill"], Entoloma incanum (Fr.) Hesler ["mouse-scented mushroom"], Entoloma sericellum (Fr.) P. Kumm. ["cream pinkgill”"], E. sericeum, and Entoloma undatum (Fr.) M.M. Moser ["wavy Entoloma"]). Other waxcap grassland surveys produced differing CHE ratios, especially having more Hygrocybe and fewer Entoloma species (Rotheroe et al. 1996; Rotheroe 2001).

Mycological red lists have been produced for many European countries. Comparing our survey with a preliminary red list from sand dunes and grasslands in the Netherlands (Arnolds 1989a) yields insights into which taxa occur in grasslands across continents and may belong on red lists for North America. In common between Ontario and the Netherlands were Cuphophyllus pratensis (Fr.) Bon ("meadow waxcap"), C. virgineus, Cyathus stercoreus (Schwein.) De Toni ("dung-loving bird's nest"), E. incanum, Entoloma cf. excentricum Bres. ("excentric pinkgill"), Entoloma mougeotii Fr. ex P. Kumm., H. conica (group), Hygrocybe glutinipes Bon. ("glutinous waxcap"), Hygrocybe flavescens (Kauffman) Singer ("golden waxcap"), Phallus hadriani Vent. ("dune stinkhorn"), and Ramariopsis subtilis (Pers.) R.H. Petersen ("slender coral"). Greater and more focussed survey efforts for these species should be conducted in North America to determine if their populations are declining as they are in the Netherlands, perhaps due to similar pressures (particularly grassland habitat loss). Our fruiting body surveys detected no species of Conocybe, Dermoloma, Lepiota, Lepista, Psathyrella, Psilocybe, Tulostoma, or Volvariella, all found in Netherlands grasslands, although some related sequences were detected below-ground (OTUs of the Agaricaceae, Bolbitiaceae, Pluteaceae, Psathyrellaceae, and unknown minor clades; Supplementary Data Sheet C; Hay et al. 2018). Differences may be reconciled with the Netherlands studies having sampled over a longer period and across more sites, perhaps representing a greater variety of habitats than our tallgrass prairie sites. More research is needed in North America to determine which taxa occur in tallgrass versus other prairies, such as Tulostoma and Volvariella that have only been found in mixedgrass prairie (Hay 2013).

Several species in our survey are new or interesting records. Entoloma tubaeforme T.H. Li, E. Battistin, W.Q. Deng \& M. Gelardi has only been recorded from under Australian Pine (Casuarina equisetifolia L.) in China. Although we did not conduct microscopy prior to destroying our specimen for sequencing, our specimen and theirs appear macromorphologically identical and our sequence and theirs are distinct from other Entoloma spp. when placed on a curated phylogram (Battistin et al. 2014; our phylogram not shown). Few records exist in MyCoPortal for Hebeloma dunense L. Corb. \& R. Heim ("dune poisonpie"); it has been recorded from sand dunes in Oregon, DBG-F-016550 and deciduous forest in Quebec, HRL1069. Our Hebeloma vaccinum Romagnesi ("willow poisonpie") specimen is the first record of this species from Canada. We found abundant $C$. undulata in only one of our sites, on open sand amongst moss. It is rarely mentioned in the literature (see Stereum tenerrimum Berk. \& Rav. and Stereum exiguum (Peck) Burt as cited in Reid 1965; Kout and Zíbarová 2013), though there are several records on MyCoPortal from across North America. Ours is only the second sequence available on GenBank and one of a few specimens from Canada.

Psathyrella ammophila (Durieu \& Lév.) P.D. Orton ("dune brittlestem") was another species limited to our sandy soil sites. This species is known from sand dunes and especially in relationship with beachgrass roots (Ammophila spp.; Watling and Rotheroe 1989) or, in this case, apparently species of other prairie grasses (Ammophila spp. were not present in our sites). Both C. undulata and P. ammophila were absent from the Netherlands grassland and dune preliminary red lists of Arnolds (1989a), but may be of conservation interest in North America. Polyporus cryptopus was not found in our surveys, but if it is rare and declining it would be an ideal candidate species for conservation of grassland fungi in North America given its ease of identification.

Although it is difficult to compare NGS studies with different objectives, methods (including primers used), taxonomic scope and scale, some commonalities and differences are apparent. Minor clades Clavariaceae and Hygrophoraceae, which showed high OTU richness in Ontario prairies, were represented among the most abundant genera of Oklahoma tallgrass prairie samples (Camarophyllopsis and Cuphophyllus, as $\mathrm{Ca}$ marophyllus; Penton et al. 2013). No conclusions as to the richness or abundance of these two families can be drawn from a study of Kansas tallgrass prairie (Jumpponen et al. 2010) except that genus Hygrocybe was detected and no genera of the Clavariaceae are listed. In Kansas, the Atheliales was the third most abundant 
order, holding $21 \%$ of Basidiomycota sequences, whereas in our study the Atheliaceae (=Atheliales; Jülich 1981) had low total relative abundance (less than 1\%; Supplementary Data Sheet D; Hay et al. 2018). Unique to our study were the Entolomataceae and Sebacinaceae (second and third most OTU rich minor clades) that were not detected in Kansas and Oklahoma prairies (Jumpponen et al. 2010; Penton et al. 2013). Similarly, a recent NGS study in grasslands of Wales, United Kingdom found many Clavariaceae and Hygrophoraceae but many fewer Entolomataceae and Sebacinaceae than in our study (Detheridge et al. 2018; Gareth Griffith pers. comm. 7 August 2018). It is unclear whether methodological factors (e.g., primers used) or site factors are behind these coarse-scale disparities. Our use of primers to the D1 region of the large ribosomal subunit, instead of part or all of the internal transcribed spacer region, may have reduced the bias towards Ascomycota, with their often shorter (and thus more readily PCR-amplified) ITS region (Asemaninejad et al. 2016). A comparison of raw sequence files from each study processed side-by-side would yield more detailed and authoritative comparisons. However, each geographic region should be sampled using the same methods and primers, ideally with multiple primers that might compensate for PCR bias, lack of resolution, or gaps in the reference database of any one primer set (Seifert et al. 2007; Asemaninejad et al. 2016; De Filippis et al. 2017). More NGS studies in North American grasslands could determine fungal composition and how it is shaped by soil condition, vegetative community, grassland management regime, and climate (c.f., Detheridge et al. 2018).

\section{Comparing above- and below-ground survey techniques}

Several studies of fungal communities have compared fruiting body surveys and below-ground molecular techniques (Table 5). Different sampling environments and methods probably explain discrepencies. Fruiting body sampling period varied from one (our study) to four years (Smith et al. 2007) with more or fewer site visits, and below-ground techniques were either cloning (Smith et al. 2007; Porter et al. 2008) or NGS (Ovaskainen et al. 2013; our study), with varying numbers of soil or wood samples collected. Earlier studies of ectomycorrhizal fungi comparing fruiting body surveys with root tip mycorrhizae often compared above- and below-ground results and found little correspondence (reviewed by Horton and Bruns 2001). Smith et al. (2007) attribute apparent lack of overlap with sampling difficulties and methodology. They showed that greater correspondence can be found by conducting fruiting body sampling visits over multiple years, making equal effort to find all fruiting body forms (epigeous, hypogeous, and resupinate species). However, even with Smith et al.'s (2007) greater sampling effort, more than half of their species were not found by both techniques. Taxa with inconspicuous corticioid fruiting bodies such as Sebacinaceae and Atheliaceae that we failed to detect above-ground were also missed by the thorough fruiting body surveys of Porter et al. (2008). Smith et al. (2007) were able to detect fruiting bodies of four species of the order Sebacinales, but this is only a fraction of the 15 Sebacinaceae OTUs found in our study.

In other cases, minor clades were not completely exclusive to one method or the other but were disproportionately represented. For example, richness of Clavariaceae was better revealed through below-ground sampling in our study. As suggested by Smith et al. (2007), it could be that inconspicuous corticioid or hypogeous species were overlooked due to infrequent fruiting, or species were cryptic (e.g., Clavariaceae: C. acuta and C. fragilis are both white fairy clubs that were initially recorded as one morphospecies but which we later identified through sequencing). It has been proposed that imbalanced representation of abundance across above- and below-ground techniques may represent different life history strategies: allocate energy into spore release via above-ground fruiting bodies or compete vegetatively below-ground (Gardes and Bruns 1996; Horton and Bruns 2001). Ovaskainen et al. (2013) found that among wood-decomposing fungi, there is no tradeoff; species with many fruiting bodies also have more mycelium. These authors outlined several different types of species-specific life-history strategies. Our limited above-ground sampling was not suited to identify life-history tradeoffs.

At coarse taxonomic scales, Porter et al. (2008) found that species-rich orders were detected using either above- or below-ground techniques but some, less species-rich orders, were missed by either technique on its own. In contrast, we found that at the major clade level (ca. order) NGS was able to detect all aboveground taxa whereas fruiting body sampling still missed many below-ground taxa. However, most species-rich taxa were still found by either technique at the minor clade (ca. family) level. In general, we found that in a grassland ecosystem, NGS produced more thorough assessments of fungal composition more efficiently than fruiting body surveys. The opposite conclusion is drawn in studies of fungi in treed ecosystems, at least with the molecular methods used for below-ground surveys of the time (Porter et al. 2008; Tóth and Barta 2010). Fungi in more arid ecosystems fruit infrequently, so below-ground molecular techniques are probably more practical (noted in Gardes and Bruns 1996). In our study and all others comparing above- and belowground techniques, using multiple techniques helped discover a more complete view of the ecosystem's fungal composition, but consideration of the ecosystem, taxa of interest, and study objectives can determine which technique(s) would be most appropriate.

\section{Limitations in methods}

Sequencing of DNA from soil samples has been criticized for including inactive fungal material when only 
TABLE 5. Statistical review of our and three other studies that collected data above-ground (fruiting body surveys) and belowground (molecular surveys from soil or wood samples) to compare numbers of shared species (species detected by both above-ground and below-ground methods).

\begin{tabular}{|c|c|c|c|c|}
\hline Study & $\begin{array}{l}\text { Our } \\
\text { study }\end{array}$ & $\begin{array}{l}\text { Ovaskainen } \\
\text { et al. }(2013)\end{array}$ & $\begin{array}{l}\text { Porter et al. } \\
\quad(2008)\end{array}$ & $\begin{array}{l}\text { Smith et al. } \\
\quad(2007)\end{array}$ \\
\hline Environment & $\begin{array}{l}\text { tallgrass } \\
\text { prairies }\end{array}$ & $\begin{array}{l}\text { Norway spruce } \\
\text { (Picea abies } \\
\text { (L.) H. Karst.) logs }\end{array}$ & $\begin{array}{l}\text { Hemlock (Tsuga } \\
\text { canadensis (L.) Carrière) } \\
\text { dominated forest }\end{array}$ & $\begin{array}{l}\text { xeric oak (Quercus) } \\
\text { woodland }\end{array}$ \\
\hline $\begin{array}{l}\text { Shared above-ground } \\
\text { (shared / total above) }\end{array}$ & $11 \%$ & $30 \%$ & $11 \%$ & $42 \%$ \\
\hline $\begin{array}{l}\text { Shared below-ground } \\
\text { (shared / total below) }\end{array}$ & $3 \%$ & $23 \%$ & $25 \%$ & $45 \%$ \\
\hline Shared (species count) & 8 & 30 & 13 & 39 \\
\hline Above (species count) & 70 & 99 & 119 & 92 \\
\hline Below(species count) & 238 & 133 & 53 & 86 \\
\hline
\end{tabular}

active fungal material should be included (Klein 2015). Our soil washing procedure helped to address this by washing away spores (inactive fungal material) and retaining only plant debris, fungal hyphae, rhizomorphs, and sclerotia (Thorn et al. 1996; Lynch and Thorn 2006). One drawback was that our two most abundant below-ground species are probably overrepresented: $M$. polyspora produces bulbils $0.1-0.2 \mathrm{~mm}$ in diameter (Weresub and LeClair 1971) and members of the Ceratobasidaceae (potentially our Ceratobasidiaceae sp. 1) produce sclerotia $0.25-0.50 \mathrm{~mm}$ in diameter (Kumar et al. 2002). These would have been selectively retained on our soil-washing sieves.

Although reference sequence datasets are constantly growing, data gaps still exist. The gaps may represent known fungi yet to be sequenced or fungi that are undescribed, perhaps due to lack of conspicuous fruiting body production or an inability to culture. Queries of OTUs from some of our minor clades unique to the below-ground sampling technique (e.g., Gomphales subclade, Pluteaceae, Cantharellales unknown family, and Russulales unknown family) did not return any confident GenBank matches. Our Pluteaceae minor clade may correspond with a "sister clade to Volvariella" (Lynch and Thorn 2006; Bahnmann 2009) and "Pluteoid clade" (Wong 2012) that continues to lack reference sequences from closely related taxa.

Given the short read lengths obtained with Illumina platforms of NGS, annotating OTUs to species-level is difficult and uncertain, and probably is the main reason that comparisons with fruiting body surveys are not usually attempted (Ovaskainen et al. 2013). We expect there are a greater number of shared species than the eight we found with identical sequences between our techniques. Our ability to detect more shared species was limited due to some unsuccessful fruiting body sequencing and the requirement of short sequences for NGS (making intra-specific gene variation difficult to account for). The expected true number of shared species can be extrapolated to 15 , assuming all fruiting body species we encountered were successfully sequenced. Degrees of gene variation are more difficult to account for and vary depending on the taxon and gene region in question. Some taxa lacked sufficient variation in the D1 LSU region to distinguish species (e.g., our Polyporaceae sensu lato OTUs) whereas other taxa seemed to be variable enough to produce a split between morphological and genetic species (e.g., $M$. elegans which was found by both techniques but not with identical sequences).

Confident identification and sequencing of fruiting bodies was sometimes limited by availability of material from the field for sequencing and microscopy work. For example, small whitish Mycena (sensu lato) were abundant and recurring in our study, but often occurred singly, providing limited material for microscopy and molecular work. A few distinct Mycena sensu stricto species and Atheniella cf. flavoalba (Fr.) Redhead, Moncalvo, Vilgalys, Desjardin, B.A. Perry ("ivory bonnet") were distinguished with microscopy and sequencing. Our unidentified Mycena sp. (sensu lato, white) could belong to Mycena (sensu stricto), Hemimycena, Delicatula, or Atheniella, which may appear superficially similar but actually cross three families. Two below-ground OTUs (M. epipterygia sp. 1 and Mycena sp. 2) were particularly abundant and may correspond with above-ground, unsequenced Mycena species. Mycena epipterygia and A. flavoalba were found in European grassland surveys (Wilkins and Patrick 1939; Gumińska 1976; Arnolds 1981). Such difficult taxa benefit from studies that include more frequent surveying than ours to increase chances of finding abundant fruitings, as well as ample time dedicated to careful and extended microscopy and consulting the taxonomic literature.

\section{Conclusions}

Our surveys of above- and below-ground fungal taxa showed that most Ontario tallgrass prairie Agaricomycete species belonged to the Clavariaceae, Entolomataceae, Sebacinaceae, Hygrophoraceae, and Polyporaceae sensu lato. Inconspicuous taxa such as the Sebacinaceae and Polyporaceae were only revealed with NGS technology. Similarly to previous studies, 
we found little correspondence between our above- and below-ground techniques at finer taxonomic scales and greater overlap at coarser scales, but NGS uncovered many taxa that fruiting body surveys missed. Thus, we stress the importance of methodological details in comparing techniques. NGS is a practical technique to determine grassland fungal community composition, but fruiting body surveys remain an important supplement and should not be neglected. In our relatively short fruiting body survey, and using recent advancements in technology (NGS, newly developed primers, and a more comprehensive GenBank reference sequence database), we took the first steps into defining Agaricomycete communities in Ontario tallgrass prairies. More research is needed to discover and better understand the fungal communities of grasslands across North America.

\section{Acknowledgements}

We thank Gareth Griffith and one anonymous reviewer for their improvements to the manuscript. Nicola Day provided critical feedback on a draft of the manuscript prior to submission. We thank Sarah Allan, Catriona Catomeris, and Aniruddho Chokroborty-Hoque for field soil collection, Dr. Greg Gloor for pipeline code, Nimalka Weerasuriya for assistance running the pipeline and data submission to the ENA, and Linxi Xie for sequencing of mushroom specimens. Henry J. Beker kindly sequenced and identified our Hebelo$m a$ specimens. We thank our multiple field site partners and specific contacts for land access permission and assistance. Thanks to the Walpole Island First Nation and the Nin.da.waab.jig Heritage Centre committee and staff for advice and contributions, including Keith Wrightman and Torey Day. We thank the Herb Gray Parkway personnel (Andrea Zolnai, Meaghan Murphy, and Barbara Macdonell), as well as the Ontario Ministry of Transportation, Ministry of Natural Resources and Forestry, and Parkway Species at Risk team (including Parkway Infrastructure Constructors, Amec Foster Wheeler, and AECOM). Thanks to the Ojibway Prairie Provincial Nature Reserve, the Elgin Stewardship Council (Jim Wigle and Bill Prieksaitis), Mary Gartshore and Peter Carson, the Nature Conservancy of Canada (Jill Crosthwaite), and the Rare Charitable Research Reserve (Jenna Quinn). Financial support was provided by a rare research scholarship to Sarah Allan and Nimalka Weerasuriya and by the Department of Biology and Faculty of Science, University of Western Ontario.

\section{Literature Cited}

Agerer, R., and K. Waller. 1993. Mycorrhizae of Entoloma saepium: parasitism or symbiosis? Mycorrhiza 3: 145-154. https://doi.org/10.1007/BF00203608

Allan, S.N. 2017. Disturbance and the community composition of arbuscular mycorrhizal fungi in Ontario tallgrass prairies. M.Sc. thesis, University of Western Ontario, London, Ontario, Canada. Accessed 23 July 2018. http://ir. lib.uwo.ca/etd/4835/.
Andre, P.M., A.K. Bartram, J.M. Truszkowski, D.G. Brown, and J.D. Neufeld. 2012. PANDAseq: paired-end assembler for illumina sequences. BMC Bioinformatics 13: 31. https://doi.org/10.1186/1471-2105-13-31

Archibold, O.W. 1995. Ecology of World Vegetation. Springer, Dordrecht, Netherlands.

Arnolds, E. 1981. Ecology and Coenology of Macrofungi in Grasslands and Moist Heathlands in Drenthe, the Netherlands. Part 1. Introduction and Synecology. J. Cramer, Vaduz, Liechtenstein.

Arnolds, E. 1982. Ecology and Coenology of Macrofungi in Grasslands and Moist Heathlands in Drenthe, the Netherlands. Part 2. Autoecology. J. Cramer, Vaduz, Liechtenstein.

Arnolds, E. 1988. The Netherlands as an environment for agarics and boletii. Pages 6-29 in Flora Agaricina Neerlandica: Critical Monographs on Families of Agarics and Boletii Occurring in the Netherlands. Volume 1. Edited by C. Bas, T.H.W. Kuyper, M.E. Noordeloos, and E.C. Vellinga. A. A. Balkema, Rotterdam, Netherlands.

Arnolds, E. 1989a. A preliminary red data list of macrofungi in the Netherlands. Persoonia 14(1): 77-125. Accessed 23 July 2018. http://www.repository.naturalis.nl/record/53 2118.

Arnolds, E. 1989b. The influence of increased fertilization on the macrofungi of a sheep meadow in Drenthe, the Netherlands. Opera Botanica 100: 7-21.

Arora, D. 1986. Mushrooms Demystified. Second Edition. Ten Speed Press, Berkeley, California, USA.

Asemaninejad, A., N. Weerasuriya, G.B. Gloor, Z. Lindo, and R.G. Thorn. 2016. New primers for discovering fungal diversity using nuclear large ribosomal DNA. PLOS ONE 11: e0159043. https://doi.org/10.1371/journal.pone. 0159043

Bahnmann, B.D. 2009. Identity and diversity of Agaricomycetes (Fungi: Basidiomycota) in temperate agricultural soils. M.Sc. thesis, University of Western Ontario, London, Ontario, Canada.

Balsdon, J., and S. Snyder. 2015. Draft 2014 annual monitoring report for plant species at risk Rt. Hon. Herb Gray Parkway volume 2. Parkway Infrastructure Constructors. Document no. PIC-83-119-0156. Revision no. A.

Barcza, D., and D. Lebedyk. 2014. Tallgrass communities mapping update. The Bluestem Banner 12(6): 2-3. Accessed 23 July 2018. http://www.tallgrassontario.org/Pub lications/BSB-September2014.pdf.

Barron, G. 1999. Mushrooms of Ontario and Eastern Canada. Lone Pine Publishing, Edmonton, Alberta, Canada.

Battistin, E., W.Q. Deng, T.H. Li, and M. Gelardi. 2014. A new species of Entoloma s.l. (Agaricales) from Nan'ao Island, south-eastern China. Sydowia 66: 257-264. https:// doi.org/10.12905/0380.sydowia66(2)2014-0257

Birkebak, J.M., J.R. Mayor, K.M. Ryberg, and P.B. Matheny. 2013. A systematic, morphological and ecological overview of the Clavariaceae (Agaricales). Mycologia 105: 896-911. https://doi.org/10.3852/12-070

Bleidorn, C. 2016. Third generation sequencing: technology and its potential impact on evolutionary biodiversity research. Systematics and Biodiversity 14: 1-8. https://doi. org/10.1080/14772000.2015.1099575

Bruns, T.D. 2012. The North American mycoflora project the first steps on a long journey. New Phytologist 196: 972974. https://doi.org/10.1111/nph. 12027

Castellano, M.A., J.E. Smith, T. O'Dell, E. Cazares, and S. Nugent. 1999. Handbook to Strategy 1 fungal taxa from the Northwest Forest Plan. Portland, Oregon: U.S. Depart- 
ment of Agriculture Forest Service Pacific Northwest Research Station. General Technical Report PNW-GTR-476.

Catling, P.M., V.R. Catling, and S.M. McKay-Kuja. 1992. The extent, floristic composition and maintenance of the Rice Lake Plains, Ontario, based on historical records. Canadian Field-Naturalist 106: 73-86. Accessed 16 July 2018. http://biodiversitylibrary.org/page/34347289.

Catomeris, C. 2015. Arbuscular mycorrhizal fungal community response to increased nitrogen deposition in a restored tallgrass prairie. B.Sc.H. thesis, University of Western Ontario, London, Ontario, Canada.

Chokroborty-Hoque, A. 2011. Arbuscular mycorrhizal fungal communities in tallgrass prairies at Walpole Island, Ontario. M.Sc. thesis, University of Western Ontario, London, Ontario, Canada.

Clarke, D.C., and M. Christensen. 1981. The soil microfungal community of a South Dakota grassland. Canadian Journal of Botany 59: 1950-1960. https://doi.org/10.1139/ b81-257

Courtecuisse, R. 2001. Current trends and perspectives for the global conservation of fungi. Pages 7-18 in Fungal Conservation: Issues and Solutions: a Special Volume of the British Mycological Society. Edited by D. Moore. Cambridge University Press, Cambridge, United Kingdom.

Cripps, C.L. 2011. A prairie polypore. Inoculum, supplement to Mycologia 62(4): 4-5.

Czederpiltz, D.L.L., T.J. Volk, and H.H. Burdsall, Jr. 2001. Field observations and inoculation experiments to determine the nature of the carpophoroids associated with Entoloma abortivum and Armillaria. Mycologia 93: 841851. https://doi.org/10.2307/3761750

De Filippis, F., M. Laiola, G. Blaiotta, and D. Ercolini. 2017. Different amplicon targets for sequencing-based studies of fungal diversity. Applied and Environmental Microbiology 83: e00905-17. https://doi.org/10.1128/AEM.00905-17

Dentinger, B.T.M., S. Margaritescu, and J.-M. Moncalvo. 2010. Rapid and reliable high-throughput methods of DNA extraction for use in barcoding and molecular systematics of mushrooms. Molecular Ecology Resources 10: 628-633. https://doi.org/10.1111/j.1755-0998.2009.02825.x

Detheridge, A.P., D. Comont, T.M. Callaghan, J. Bussell, G. Brand, D. Gwynn-Jones, J. Scullion, and G.W. Griffith. 2018. Vegetation and edaphic factors influence rapid establishment of distinct fungal communities on former coal-spoil sites. Fungal Ecology 33: 92-103. https://doi. org/10.1016/j.funeco.2018.02.002

Dewsbury, D.R., S.L. Stephenson, and J.-M. Moncalvo. 2006. A first survey of mushroom diversity in four Maryland national parks. Poster PDF. Accessed 1 June 2017. http://www.nps.gov/cue/events/spotlight08/Spotlight08 posters_PDFs/MushroomSurveyPoster_Dewsbury.pdf.

Dickie, I.A., B.T.M. Dentinger, P.G. Avis, D.J. McLaughlin, and P.B. Reich. 2009. Ectomycorrhizal fungal communities of oak savanna are distinct from forest communities. Mycologia 101: 473-483. https://doi.org/10.3852/08-178

Ecological Stratification Working Group. 1995. A national ecological framework for Canada. Agriculture and AgriFood Canada, Research Branch, Centre for Land and Biological Resources Research and Environment Canada, State of the Environment Directorate, Ecozone Analysis Branch, Ottawa-Hull, Ontario. Accessed 1 June 2017. http://sis. agr.gc.ca/cansis/publications/ecostrat/cad_report.pdf.

Edgar, R.C. 2004. MUSCLE: multiple sequence alignment with high accuracy and high throughput. Nucleic Acids Research 32: 1792-1797. https://doi.org/10.1093/nar/gkh 340
Edgar, R.C. 2010. Search and clustering orders of magnitude faster than BLAST. Bioinformatics 26: 2460-2461. https:// doi.org/10.1093/bioinformatics/btq461

Edgar, R.C., B.J. Haas, J.C. Clemente, C. Quince, and R. Knight. 2011. UCHIME improves sensitivity and speed of chimera detection. Bioinformatics 27: 2194-2200. https:// doi.org/10.1093/bioinformatics/btr381

Environment Canada. 2014. Species at risk: a guide to Canada's species at risk in the prairie provinces. Accessed 12 January 2019. http://publications.gc.ca/collections/collec tion_2016/eccc/CW66-230-2015-eng.pdf.

Eom, A.-H., D.C. Hartnett, and G.W.T. Wilson. 2000. Host plant species effects on arbuscular mycorrhizal fungal communities in tallgrass prairie. Oecologia 122: 435-444. https: //doi.org/10.1007/s004420050050

Gabel, A.C., and M.L. Gabel. 2011. New records of gasteroid and secotioid fungi from sand dunes in northwestern South Dakota. Proceedings of the South Dakota Academy of Science 90: 125-136.

Gardes, M., and T.D. Bruns. 1996. Community structure of ectomycorrhizal fungi in a Pinus muricata forest: aboveand below-ground views. Canadian Journal of Botany 74: 1572-1583. https://doi.org/10.1139/b96-190

Gibson, D.J. 2009. Grasses and Grassland Ecology. Oxford University Press, New York, USA

Goos, R.D. 1960. Basidiomycetes isolated from soil. Mycologia 52: 661-663. https://doi.org/10.2307/3756104

Griffith, G.W., J.G.P. Gamarra, E.M. Holden, D. Mitchel, A. Graham, D.A. Evans, S.E. Evans, C. Aron, M.E. Noordeloos, P.M. Kirk, S.L.N. Smith, R.G. Woods, A.D. Hale, G.L. Easton, D.A. Ratkowsky, D.P. Stevens, and H. Halbwachs. 2013. The international conservation importance of Welsh 'waxcap' grasslands. Mycosphere 4: 969-984. https://doi.org/10.5943/mycosphere/4/5/10

Griffith, G.W., A. Graham, R.G. Woods, G.L. Easton, and H. Halbwachs. 2014. Effect of biocides on the fruiting of waxcap fungi. Fungal Ecology 7: 67-69. https://doi.org/ 10.1016/j.funeco.2013.09.004

Griffith, G.W., and K. Roderick. 2008. Saprotrophic basidiomycetes in grasslands: distribution and function. Pages 277-299 in Ecology of Saprotrophic Basidiomycetes. British Mycological Society Symposia Series, Volume 28. Edited by L. Boddy, J.C. Frankland, and P. van West. Elsevier Ltd. Academic Press, Amsterdam, Netherlands. https:// doi.org/10.1016/S0275-0287(08)80017-3

Gumińska, B. 1976. Macromycetes of meadows in Pieniny National Park. Acta Mycologica 12: 3-75. https://doi.org/ 10.5586/am.1976.001

Hausner, G., J. Reid, and G.R. Klassen. 1993. On the subdivision of Ceratocystis s.1., based on partial ribosomal DNA sequences. Canadian Journal of Botany 71: 52-63. https://doi.org/10.1139/b93-007

Hay, C.R.J. 2013. An initial survey of mushrooms in Grasslands National Park. Blue Jay 71: 190-200. Accessed 15 June 2019. https://bluejayjournal.ca/index.php/bluejay/arti cle/view/348/345.

Hay, C.R.J., R.G. Thorn, and C.R. Jacobs. 2018. Data from: Taxonomic survey of Agaricomycetes (Fungi: Basidiomycota) in Ontario tallgrass prairies determined by fruiting body and soil rDNA sampling. Dryad Digital Repository. https://doi.org/10.5061/dryad.sm0kk00

Hibbett, D.S., R. Bauer, M. Binder, A.J. Giachini, K. Hosaka, A. Justo, E. Larsson, K.H. Larsson, J.D. Lawrey, O. Miettinen, L.G. Nagy, R.H. Nilsson, M. Weiss, and R.G. Thorn. 2014. Agaricomycetes. Pages 373-429 in The Mycota VII Part A. Systematics and Evolution. Second Edi- 
tion. Edited by D.J. McLaughlin and J.W. Spatafora. J.W. Springer-Verlag, Berlin, Germany.

Horton, T.R., and T.D. Bruns. 2001. The molecular revolution in ectomycorrhizal ecology: peeking into the blackbox. Molecular Ecology 10: 1855-1871. https://doi.org/10. 1046/j.0962-1083.2001.01333.x

Hunt, J., L. Boddy, P.F. Randerson, and H.J. Rogers. 2004. An evaluation of $18 \mathrm{~S}$ rDNA approaches for the study of fungal diversity in grassland soils. Microbial Ecology 47: 385-395. https://doi.org/10.1007/s00248-003-2018-3

Jülich, W. 1981. Higher taxa of Basidiomycetes. Bibliotecha Mycologica 85: 1-485.

Jumpponen, A., and K.L. Jones. 2014. Tallgrass prairie soil fungal communities are resilient to climate change. Fungal Ecology 10: 44-57. https://doi.org/10.1016/j.funeco.2013. 11.003

Jumpponen, A., K.L. Jones, and J. Blair. 2010. Vertical distribution of fungal communities in tallgrass prairie soil. Mycologia 102: 1027-1041. https://doi.org/10.3852/09-316

Kearse, M., R. Moir, A. Wilson, S. Stones-Havas, M. Cheung, S. Sturrock, S. Buxton, A. Cooper, S. Markowitz, C. Durn, T. Thierer, B. Ashton, P. Meintjes, and A. Drummond. 2012. Geneious Basic: an integrated and extendable desktop software platform for the organization and analysis of sequence data. Bioinformatics 28: 16471649. https://doi.org/10.1093/bioinformatics/bts 199

Keizer, P. 1993. The influence of nature management on the macromycete flora. Pages 251-270 in Fungi of Europe: Investigation, Recording and Conservation. Edited by D.N. Pegler, L. Boddy, B. Ing, P.M. Kirk, and S. Dickerson. The Royal Botanic Gardens, Kew, United Kingdom.

Kirk, P.M., P. Cannon, and J. Stalpers. 2008. Dictionary of the Fungi, 10th Edition. CABI, Wallingford, United Kingdom.

Klein, D.A. 2015. QIIME: Better described as EMSAP? Microbe 10: 90-91. https://doi.org/10.1128/microbe.10. 90.1

Kobayashi, H., and A. Yamada. 2003. Chlamydospore formation of Entoloma clypeatum $\mathrm{f}$. hybridum on mycorrhizas and rhizomorphs associated with Rosa multiflora. Mycoscience 44: 61-62. https://doi.org/10.1007/S10267-002-00 80-1

Koper, N., K.E. Mozel, and D.C. Henderson. 2010. Recent declines in northern tall-grass prairies and effects of patch structure on community persistence. Biological Conservation 143: 220-229. https://doi.org/10.1016/j.biocon.2009. 10.006

Kout, J., and L. Zíbarová. 2013. Revision of the genus Cotylidia (Basidiomycota, Hymenochaetales) in the Czech Republic. Czech Mycology 65: 1-13.

Kumar, S., K. Sivasithamparam, and M.W. Sweetingham. 2002. Prolific production of sclerotia in soil by Rhizoctonia solani anastomosis group (AG) 11 pathogenic on lupin. Annals of Applied Biology 141: 11-18. https://doi.org/ 10.1111/j.1744-7348.2002.tb00190.x

Lindahl, B.D., R.H. Nilsson, L. Tedersoo, K. Abarenkov, T. Carlsen, R. Kjøller, U. Kõljalg, T. Pennanen, S. Rosendahl, J. Stenlid, and H. Kauserud. 2013. Fungal community analysis by high-throughput sequencing of amplified markers - a user's guide. New Phytologist 199: 288-299. https://doi.org/10.1111/nph.12243

Lynch, M.D.J., and R.G. Thorn. 2006. Diversity of basidiomycetes in Michigan agricultural soils. Applied and Environmental Microbiology 72: 7050-7056. https://doi.org/10. 1128/AEM.00826-06
Maggi, O., A.M. Persiani, M.A. Casado, and F.D. Pineda. 2005. Effects of elevation, slope position and livestock exclusion on microfungi isolated from soils of Mediterranean grasslands. Mycologia 97: 984-995. https://doi. org/10.1080/15572536.2006.11832748

Malloch, D., and R.G. Thorn. 1985. The occurrence of ectomycorrhizae in some species of Cistaceae in North America. Canadian Journal of Botany 63: 872-875. https://doi.org/ 10.1139/b85-113

McKinley, V.L., A.D. Peacock, and D.C. White. 2005. Microbial community PLFA and PHB responses to ecosystem restoration in tallgrass prairie soils. Soil Biology and Biochemistry 37: 1946-1958. https://doi.org/10.1016/j.soilbio. 2005.02.033

Mitchel, D. 2010. Survey of the grassland fungi of the Vice County of West Galway and the Aran Islands. Report to the Heritage Council. Accessed 24 March 2019. https://www. aber.ac.uk/waxcap/downloads/Mitchel10-WestGalwayWax capSurvey2010.pdf.

Mycological Society of Toronto. 2005a. Fungal flora of Carden plain Fall 2005. Accessed 15 July 2018. https://www. myctor.org/forays/past-forays/fungal-flora-of-carden-plain fall-2005.

Mycological Society of Toronto. 2005b. Fungal flora of the Carden plain - interim report June 2005. Accessed 15 July 2018. https:/www.myctor.org/forays/past-forays/fungalflora-of-carden-plain-interim-report-june-2005.

Newton, A.C., L.M. Davy, E. Holden, A. Silverside, R. Watling, and S.D. Ward. 2003. Status, distribution and definition of mycologically important grasslands in Scotland. Biological Conservation 111: 11-23. https://doi.org/ 10.1016/S0006-3207(02)00243-4

Nilsson, R.H., C. Wurzbacher, M. Bahram, V.R.M. Coimbra, E. Larsson, L. Tedersoo, J. Eriksson, C. Duarte, S. Svantesson, M. Sánchez-García, M.K. Ryberg, E. Kristiansson, and K. Abarenkov. 2016. Top 50 most wanted fungi. MycoKeys 12: 29-40. https://doi.org/10.3897/my cokeys. 12.7553

Noordeloos, M.E. 2004. Entoloma s.l. Supplement. Fungi Europaei Volume 5A. Candusso. Alassio, Italy.

Noss, R.F., E.T. LaRoe, III, and J.M. Scott. 1995. Endangered ecosystems of the United States: a preliminary assessment of loss and degradation. Biological Report 28. USDI National Biological Service, Washington, DC, USA. Accessed 21 December 2017. https://iucnrle.org/static/media/ uploads/references/background/assessments/noss-etal-1995 endangered-ecosystems-usa-preliminary-assessment-lossdegradation-en.pdf.

Ovaskainen, O., D. Schigel, H. Ali-Kovero, P. Auvinen, L. Paulin, B. Nordén, and J. Nordén. 2013. Combining highthroughput sequencing with fruit body surveys reveals contrasting life-history strategies in fungi. The ISME Journal 7: 1696-1709. https://doi.org/10.1038/ismej.2013.61

Peay, K.G., P.G. Kennedy, and J.M. Talbot. 2016. Dimensions of biodiversity in the Earth mycobiome. Nature Reviews Microbiology 14: 434-447. https://doi.org/10.1038/ nrmicro.2016.59

Penton, C.R., D. St. Louis, J.R. Cole, Y. Luo, L. Wu, E.A.G. Schuur, J. Zhou, and J.M. Tiedje. 2013. Fungal diversity in permafrost and tallgrass prairie soils under experimental warming conditions. Applied and Environmental Microbiology 79: 7063-7072. https://doi.org/10.1128/AEM.01 702-13

Peterson, S.W., and C.P. Kurtzman. 1991. Ribosomal-RNA sequence divergence among sibling species of yeasts. Sys- 
tematic and Applied Microbiology 14: 124-129. https://doi. org/10.1016/S0723-2020(11)80289-4

Polach, I. 1992. A survey of the fleshy Basidiomycete fungi of Kejimkujik National Park, N.S., with emphasis on pollution indicators. M.Sc. thesis, Acadia University, Wolfville, Nova Scotia, Canada.

Porter, T.M., J.E. Skillman, and J.-M. Moncalvo. 2008. Fruiting body and soil rDNA sampling detects complementary assemblage of Agaricomycotina (Basidiomycota, Fungi) in a hemlock-dominated forest plot in southern Ontario. Molecular Ecology 17: 3037-3050. https://doi.org/ 10.1111/j.1365-294X.2008.03813.x

QGIS Development Team. 2017. QGIS Geographic Information System. Open Source Geospatial Foundation Project. Accessed 23 December 2017. https://www.qgis.org/.

Quinlan, P. 2005. A landowner's guide to tallgrass prairie and savanna management in Ontario. Tallgrass Ontario, Ridgetown, Ontario. Accessed 1 June 2017. http://tallgrassont ario.org/Publications/LandownersGuide2005.pdf.

Redhead, S.A. 1989. A biogeographical overview of the Canadian mushroom flora. Canadian Journal of Botany 67: 3003-3062. https://doi.org/10.1139/b89-384

Reid, D.A. 1965. A monograph of the stipitate stereoid fungi. Nova Hedwigia Beihefte 18: 1-382.

Rinaldi, A.C., O. Comandini, and T.W. Kuyper. 2008. Ectomycorrhizal fungal diversity: separating the wheat from the chaff. Fungal Diversity 33: 1-45.

Rodger, L. 1998. Tallgrass communities of southern Ontario: a recovery plan. Prepared for World Wildlife Fund Canada and the Ontario Ministry of Natural Resources. Accessed 1 June 2017. http://tallgrassontario.org/Publications/Tallgrass RecoveryPlan.pdf.

Rotheroe, M. 2001. A preliminary survey of waxcap grassland indicator species in south Wales. Pages 120-135 in Fungal Conservation: Issues and Solutions: a Special Volume of the British Mycological Society. Edited by D. Moore. Cambridge University Press, Cambridge, United Kingdom.

Rotheroe, M., A. Newton, S. Evans, and J. Feehan. 1996. Waxcap-grassland survey. Mycologist 10: 23-25. https:// doi.org/10.1016/s0269-915x(96)80046-2

RStudio Team. 2016. RStudio: integrated development for R. RStudio, Inc., Boston, Massachusetts, USA. Accessed 20 April 2017. http://www.rstudio.com/.

Samson, F.B., and F.L. Knopf. 1996. Prairie Conservation: Preserving North America's Most Endangered Ecosystem. Island Press, Washington, DC, USA.

Sanger, F., S. Nicklen, and A.R. Coulson. 1977. DNA sequencing with chain-terminating inhibitors. Proceedings of the National Academy of Sciences 74: 5463-5467. https: //doi.org/10.1073/pnas.74.12.5463

Seifert, K.A., R.A. Samson, J.R. deWaard, J. Houbraken, C.A. Lévesque, J.-M. Moncalvo, G. Louis-Seize, and P.D.N. Hebert. 2007. Prospects for fungus identification using CO1 DNA barcodes, with Penicillium as a test case. Proceedings of the National Academy of Sciences 104: 3901-3906. https://doi.org/10.1073/pnas.0611691104

Shokralla, S., J.L. Spall, J.F. Gibson, and M. Hajibabaei. 2012. Next-generation sequencing technologies for environmental DNA research. Molecular Ecology 21: 1794 1805. https://doi.org/10.1111/j.1365-294X.2012.05538.x

Sims, P.L. 1988. Grasslands. Pages 323-356 in North American Terrestrial Vegetation. Edited by M.G. Barbour and W.D. Billings. Cambridge University Press, New York, USA.
Smith, M.E., G.W. Douhan, and D.M. Rizzo. 2007. Ectomycorrhizal community structure in a xeric Quercus woodland based on rDNA sequence analysis of sporocarps and pooled roots. New Phytologist 174: 847-863. https://doi.org/10. 1111/j.1469-8137.2007.02040.x

Smith, S.E., and D.J. Read. 2008. Mycorrhizal Symbiosis. Third Edition. Academic Press, Amsterdam, Netherlands.

Statistics Canada. 2011. 2011 Census - Boundary Files. Digital Boundary File for Provinces/Territories ("gpr_000b11 a_e.zip"). Accessed 24 December 2017. http://www12.stat can.gc.ca/census-recensement/2011/geo/bound-limit/boundlimit-2011-eng.cfm.

Stover, H.J., R.G. Thorn, J.M. Bowles, M.A. Bernards, and C.R. Jacobs. 2012. Arbuscular mycorrhizal fungi and vascular plant species abundance and community structure in tallgrass prairies with varying agricultural disturbance histories. Applied Soil Ecology 60: 61-70. https://doi.org/10. 1016/j.apsoil.2012.02.016

Taberlet, P., E. Coissace, M. Hajibabaei, and L.H. Rieseberg. 2012. Environmental DNA. Molecular ecology 21: 1789-1793. https://doi.org/10.1111/j.1365-294X.2012.05 542.x

Tamura, K., G. Stecher, D. Peterson, A. Filipski, and S. Kumar. 2013. MEGA6: Molecular Evolutionary Genetics Analysis version 6.0. Molecular Biology and Evolution 30: 2725-2729. https://doi.org/10.1093/molbev/mst197

Taylor, D.L., W.A. Walters, N.J. Lennon, J. Bochicchio, A. Krohn, J.G. Caporaso, and T. Pennanen. 2016. Accurate estimation of fungal diversity and abundance through improved lineage-specific primers optimized for Illumina amplicon sequencing. Applied and Environmental Microbiology 82: 7217-7226. https://doi.org/10.1128/AEM.025 76-16

Tedersoo, L., T.W. May, and M.E. Smith. 2010. Ectomycorrhizal lifestyle in fungi: global diversity, distribution, and evolution of phylogenetic lineages. Mycorrhiza 20: 217263. https://doi.org/10.1007/s00572-009-0274-x

Tedersoo, L., B. Mohammad, S. Põlme, U. Kõljalg, N.S. Yorou, R. Wijesundera, L. Villareal Ruiz, A.M. VascoPalacios, P.Q. Thu, A. Suija, M.E. Smith, C. Sharp, E. Saluveer, A. Saitta, M. Rosas, T. Riit, D. Ratkowsky, K. Pritsch, K. Põldmaa, M. Piepenbring, C. Phosri, M. Peterson, K. Parts, K. Pärtel, E. Otsing, E. Nouhra, A.L. Njouonkou, R.H. Nilsson, L.N. Morgado, J. Mayor, T.W. May, L. Majuakim, D.J. Lodge, S.S. Lee, K.H. Larsson, P. Kohout, K. Hosaka, I. Hiiesalu, T.W. Henkel, H. Harend, L.D. Guo, A. Greslebin, G. Grelet, J. Geml, G. Gates, W. Dunstan, C. Dunk, R. Drenkhan, J. Dearnaley, A. De Kesel, T. Dang, X. Chen, F. Buegger, F.Q. Brearley, G. Bonito, S. Anslan, S. Abell, and K. Abarenkov. 2014. Global diversity and geography of soil fungi. Science 346: 1078-1088. https://doi.org/10.1126/ science. 1256688

Thorn, R.G., C.A. Reddy, D. Harris, and E.A. Paul. 1996. Isolation of saprophytic basidiomycetes from soil. Applied and Environmental Microbiology 62: 4288-4292.

Tomaszewska, A., J. Luszczyńskiet, L. Lechowicz, and M. Chrapek. 2015. Selected rare and protected macrofungi (Agaricomycetes) as bioindicators of communities of xerothermic vegetation in the Nida Basin. Acta Mycologica 50: 1058-1070. https://doi.org/10.5586/am.1058

Tóth, B.B., and Z. Barta. 2010. Ecological studies of ectomycorrhizal fungi: an analysis of survey methods. Fungal Diversity 45: 3-19. https://doi.org/10.1007/s13225-010-0052-2 
United States Census Bureau. 2016. Cartographic Boundary Shapefiles - States. 2016 U.S. States Boundary Shapefile at 500k resolution ("cb 2016 us state 500k.zip"). Accessed 24 December 2017. https://www.census.gov/geo/maps-da ta/data/cbf/cbf state.html.

Vilgalys, R., and M. Hester. 1990. Rapid genetic identification and mapping of enzymatically amplified ribosomal DNA from several Cryptococcus species. Journal of Bacteriology 172: 4238-4246. https://doi.org/10.1128/jb.172. 8.4238-4246.1990

Voitk, A. 2017. Arrhenia subglobisemen. Omphalina 8(5): 19. Accessed 3 August 2018. http://www.nlmushrooms.ca/ omphaline/O-VIII-5.pdf.

Wang, Q., G.M. Garrity, J.M. Tiedje, and J.R. Cole. 2007. Naïve bayesian classifier for rapid assignment of rRNA sequences into the new bacterial taxonomy. Applied and Environmental Microbiology 73: 5261-5267. https://doi. org/10.1128/AEM.00062-07

Warcup, J.H. 1951. Studies on the growth of Basidiomycetes in soil. Annals of Botany 15: 305-318. https://doi.org/10. 1093/oxfordjournals.aob.a083283

Warcup, J.H. 1959. Studies on Basidiomycetes in soil. Transactions of the British Mycological Society 42: 45-52. https: //doi.org/10.1016/S0007-1536(59)80065-6

Warcup, J.H., and P.H.B. Talbot. 1962. Ecology and identity of mycelia isolated from soil. Transactions of the British Mycological Society 45: 495-518. https://doi.org/ 10.1016/S0007-1536(62)80010-2

Warcup, J.H., and P.H.B. Talbot. 1963. Ecology and identity of mycelia isolated from soil II. Transactions of the British Mycological Society 46: 465-472. https://doi.org/10.10 16/S0007-1536(63)80045-5

Warcup, J.H., and P.H.B. Talbot. 1965. Ecology and identity of mycelia isolated from soil III. Transactions of the British Mycological Society 48: 249-259. https://doi.org/10.1016 /S0007-1536(65)80090-0

Watling, R., and M. Rotheroe. 1989. Macrofungi of sand dunes. Proceedings of the Royal Society of Edinburgh. Section B. Biological Sciences 96: 111-126. https://doi.org/ $10.1017 / \mathrm{s} 0269727000010885$
Weiss, M., M.A. Selosse, K.H. Rexer, A. Urban, and F. Oberwinkler. 2004. Sebacinales: a hitherto overlooked cosm of heterobasidiomycetes with a broad mycorrhizal potential. Mycological Research 108: 1003-1010. https:// doi.org/10.1017/S0953756204000772

Weiss, M., Z. Sýkorová, S. Garnica, K. Riess, F. Martos, C. Krause, F. Oberwinkler, R. Bauer, and D. Redecker. 2011. Sebacinales everywhere: previously overlooked ubiquitous fungal endophytes. PLoS One 6: e16793. https://doi. org/10.1371/journal.pone.0016793

Weresub, L.K., and P.M. LeClair. 1971. On Papulaspora and bulbilliferous Basidiomycetes Burgoa and Minimedusa. Canadian Journal of Botany 49: 2203-2213. https://doi. org/10.1139/b71-308

Whittaker, R.H. 1975. Communities and Ecosystems. MacMillan, New York, USA.

Wicklow, D.T., and K. Angel. 1974. A preliminary survey of the Coprophilous fungi from a semi-arid grassland in Colorado. Technial Report No. 259. Grassland Biome. U.S. International Biological Program (IBP). Accessed 15 July 2018. http://hdl.handle.net/10217/16002.

Wilkins, W.H., and S.H.M. Patrick. 1939. The ecology of larger fungi III. Constancy and frequency of grassland species with special reference to soil types. Annals of Applied Biology 26: 25-46. https://doi.org/10.1111/j.1744-7348. 1939.tb06954.x

Wilkinson, L. 2011. Venneuler: Venn and Euler Diagrams. R package version 1.1-0. Accessed 1 June 2017. https://CR AN.R-project.org/package $=$ venneuler.

Wong, J.R. 2012. Impacts of agricultural disturbance on communities of selected soil fungi (Agaricomycetes). M.Sc. thesis, University of Western Ontario, London, Ontario, Canada.

Zhou, J.L., L. Zhu, H. Chen, and B.K. Cui. 2016. Taxonomy and phylogeny of Polyporus group Melanopus (Polyporales, Basidiomycota) from China. PLOS ONE 11: e0159495. https://doi.org/10.1371/journal.pone.0159495

Received 28 December 2017

Accepted 4 January 2019

\section{Supplementary Material:}

Spreadsheets containing metadata and data are available from The Canadian Field-Naturalist and from the Dryad Digital Repository: https://doi.org/10.5061/dryad.sm0kk00.

Sheet A. Above-ground (mushroom) species, authority, and associated minor (ca. family) and major (ca. order) clade placement.

Sheet B. Above-ground (mushroom) data as individuals across site visits.

Sheet C. Below-ground (soil sample rDNA) OTU (Operational Taxonomic Unit) taxonomic annotations, and associated minor (ca. family) and major (ca. order) clade placement.

Sheet D. Below-ground (soil sample rDNA) data as OTU (Operational Taxonomic Unit) reads per site visit.

Sheet E. Raw data for all specimens (above-ground, i.e., mushrooms) collected or otherwise recorded as observations in this study. 